\title{
Coaches' Preparedness for Sudden Death Conditions in Secondary School Athletics in West Virginia
}

Jillian Mary Sarm

jms0122@mix.wvu.edu

Follow this and additional works at: https://researchrepository.wvu.edu/etd

Part of the Sports Medicine Commons, and the Sports Sciences Commons

\section{Recommended Citation}

Sarm, Jillian Mary, "Coaches' Preparedness for Sudden Death Conditions in Secondary School Athletics in West Virginia" (2019). Graduate Theses, Dissertations, and Problem Reports. 3787.

https://researchrepository.wvu.edu/etd/3787

This Thesis is protected by copyright and/or related rights. It has been brought to you by the The Research Repository @ WVU with permission from the rights-holder(s). You are free to use this Thesis in any way that is permitted by the copyright and related rights legislation that applies to your use. For other uses you must obtain permission from the rights-holder(s) directly, unless additional rights are indicated by a Creative Commons license in the record and/ or on the work itself. This Thesis has been accepted for inclusion in WVU Graduate Theses, Dissertations, and Problem Reports collection by an authorized administrator of The Research Repository @ WVU. For more information, please contact researchrepository@mail.wvu.edu. 

Conditions in Secondary School Athletics in West Virginia

Jillian Mary Sarm

Follow this and additional works at: https://researchrepository.wvu.edu/etd

Part of the Sports Medicine Commons, and the Sports Sciences Commons 
Coaches' Preparedness for Sudden Death Conditions in Secondary School Athletics in West Virginia.

Jillian M. Sarm, LAT, ATC

Thesis submitted to the

College of Physical Activity and Sport Science

at West Virginia University

in partial fulfillment of the requirements

for the degree of

Master of Science

in

Athletic Training

Michelle A. Sandrey, PhD, ATC, Chair

Damien Clement, PhD, ATC, CMPC, NCC

Guy Hornsby, PhD, CSCS*D

Department of Sport Sciences

Morgantown, West Virginia

2019

Key words: medical emergency, emergency action plan, athletic trainer

Copyright 2019 Jillian Sarm 


\title{
ABSTRACT
}

Coaches' Preparedness for Sudden Death Conditions in Secondary School Athletics in West Virginia

\author{
Jillian M. Sarm, LAT, ATC
}

Context: Coaches in the secondary school setting may encounter and be expected to provide emergency medical care for student athletes in the absence of a healthcare professional such as athletic trainers. The National Athletic Trainers' Association (NATA) categorized ten sudden death conditions which are common in athletics and may warrant a medical emergency. Since the coaches may not be cognizant of these common sudden death conditions, they may not be prepared to handle a medical emergency which threatens the life of student athletes. Objective: Determine if West Virginia Secondary School Activities Commission (WVSSAC) coaches are aware and prepared to provide care for sudden death conditions in athletics and determine the availability and use of an emergency action plan (EAP) for athletics. Design: The study was a prospective exploratory questionnaire analysis. Setting: WVSSAC secondary school coaches. Patients and Other Participants: Two-hundred and twenty-eight participants included any current coaches in the secondary school level who provided an e-mail to the WVSSAC. The potential number of participants included the approximately 2,000 members of the WVSSAC creating a response rate of 10\%. Participants were excluded if they were not members of the WVSSAC and under the age of 18. Intervention: Participants contacted through the WVSSAC were provided a link in the cover letter to the questionnaire. After initial contact, participants were contacted by e-mail through the WVSSAC with a follow up letter with a link to the questionnaire to encourage participation or to thank the participants for prior participation two weeks after the initial cover letter was sent. The questionnaire was available for participants to complete for a total of three weeks after the initial contact. The questionnaire contained 18 questions regarding EAPs, awareness, preparedness, and provision of care for sudden death conditions, and health care provider along with demographic information. Main Outcome Measures: Difference of coaches' preparedness of sudden death conditions including asthma, catastrophic brain injuries, cervical spine injuries, diabetes, exertional heat stroke, exertional hyponatremia, exertional sickling, head-down contact in football, lightning, and sudden cardiac arrest with an athletic trainer and without, coaches' preparedness after completing the WVSSAC Coaching Course or not, and the availability of an athletics EAP. Results: Awareness frequencies were highest for exertional heat stroke $(96.1 \%)$ and sudden cardiac arrest (94.7\%) as well as for preparedness

(90.8\% and $87.3 \%)$, respectively. Sixty-three percent of participants with an athletic trainer as the health care provider reported the availability of an EAP. There was a significant relationship between the health care provider and coaches' preparedness to provider care for asthma $\left(\chi^{2}{ }_{1}\right.$, ${ }_{228}=23.621$, $\mathrm{P}=0.005, \mathrm{cc}=0.327)$ and head-down contact in football $\left(\chi_{1,228}^{2}=20.901, \mathrm{P}=0.013, \mathrm{cc}=0.312\right)$. Nine of 10 sudden death conditions reported higher preparedness rates after completion of the WVSSAC Coaching Course. There were significant relationships of coaches' preparedness for asthma $(\mathrm{p}=0.005)$ and head-down contact in football $(\mathrm{p}=0.013)$ and health care provider. Conclusion: West Virginia secondary school coaches are more aware than prepared to provide care for athletes experiencing sudden death conditions. With an athletic trainer as the health care provider, preparedness rates were higher than all other health care providers. The WVSSAC Coaching Course better prepared coaches for sudden death conditions, however additional courses for specific conditions such as asthma and diabetes can increase coaches' awareness and preparedness. 


\section{ACKNOWLEDGEMENTS}

Dr. Sandrey - Thank you for your patience, exponential knowledge, and dedication to me, this study, and my classmates the past two years. I cannot thank you enough for all of opportunities you have given us to improve ourselves as athletic trainers and individuals.

Dr. Clement and Dr. Hornsby - Without your time, consideration, and utmost expertise, I would not be in this incredible position. Thank you for granting me the ability to explore this topic and for your experiences to create this study.

My Parents - Thank you for nothing but support throughout college and graduate school. I would never be in this spot without your love and understanding my entire life. I love you both.

John - My time in West Virginia has been very much worthwhile because of you. Thank you for your love. Thank you for everything. Thank you for you.

Matt and Ty - This project was not easy but completing it with you both has been a wild ride. Thank you for tolerating me and only striving to help us all through this experience.

Mr. Bernie Dolan and the WVSSAC - Thank you for answering my many questions and to ultimately provide access to members for this survey to take place. Please thank the entire WVSSAC Executive Board, athletic directors, and most importantly, the coaches of West Virginia. I am eternally grateful. 


\section{TABLE OF CONTENTS}

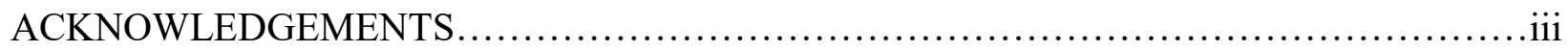

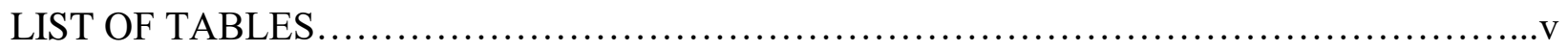

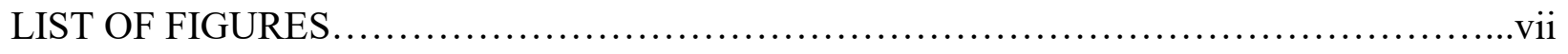

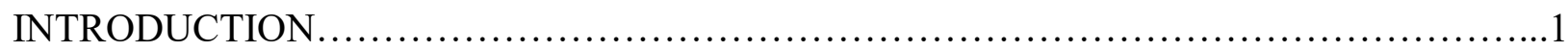

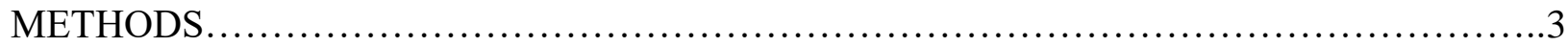

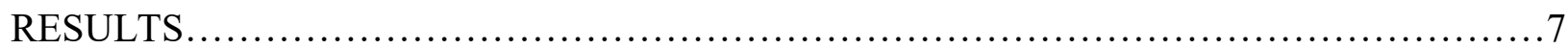

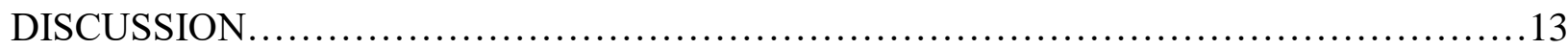

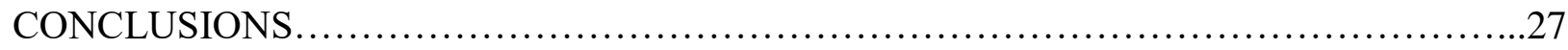

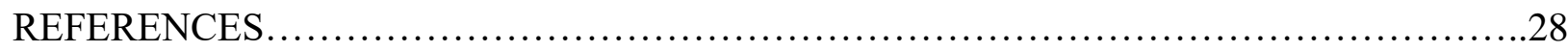

APPENDICES

APPENDIX A. THE PROBLEM............................................ 34

APPENDIX B. LITERATURE REVIEW ....................................41

APPENDIX C. ADDITIONAL METHODS .....................................65

APPENDIX D. ADDITIONAL RESULTS ...................................... 71

APPENDIX E. RECOMMENDATIONS FOR FUTURE RESEARCH...............81

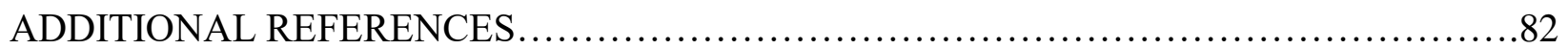




\section{LIST OF TABLES}

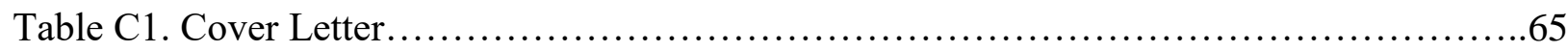

Table C2. Follow Up Cover Letter.....................................................66

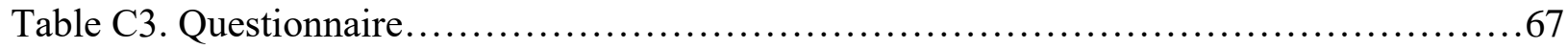

Table D1. Level of Education.............................................................. 71

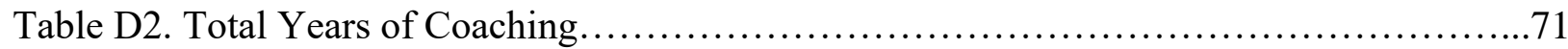

Table D3. Years Coaching at the High School Level.........................................71

Table D4. High School Sport(s) Coaching Position........................................71

Table D5. Coaching Certifications and Courses.......................................... 72

Table D6. Health Care Provider.......................................................... 72

Table D7. Coaches' Awareness of Sudden Death Conditions in Athletics.......................72

Table D8. Coaches' Preparedness of Sudden Death Conditions in Athletics....................73

Table D9. Coaches' Provision of Care for Sudden Death Conditions and Activation of the

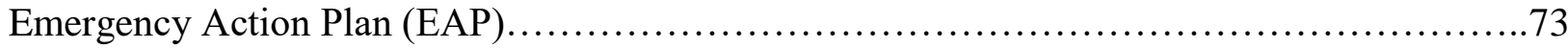

Table D10. Health Care Provider and Availability of the EAP ................................73

Table D11. Health Care Provider and Prepared to Provide Care for Asthma.....................74

Table D12. Health Care Provider and Prepared to Provide Care for Catastrophic Brain

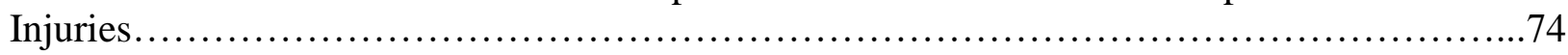

Table D13. Health Care Provider and Prepared to Provide Care for Cervical Spine Injuries.....74

Table D14. Health Care Provider and Prepared to Provide Care for Diabetes...................75

Table D15. Health Care Provider and Prepared to Provide Care for Exertional Heat Stroke......75

Table D16. Health Care Provider and Prepared to Provide Care for Exertional Hyponatremia...75

Table D17. Health Care Provider and Prepared to Provide Care for Exertional Sickling.........76 


\section{LIST OF TABLES CONTINUED}

Table D18. Health Care Provider and Prepared to Provide Care for Head-Down Contact in

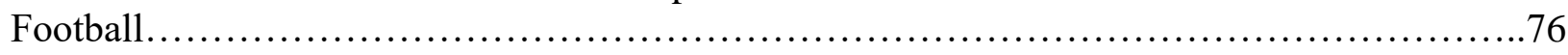

Table D19. Health Care Provider and Prepared to Provide Care for Lightning.....................76

Table D20. Health Care Provider and Prepared to Provide Care for Sudden Cardiac Arrest......77

Table D21. WVSSAC Coaching Course and Preparedness for Sudden Death Conditions.........77

Table D22. NFHS Course Completion and Preparedness for Sudden Death Conditions..........78

Table D23. Years of Coaching Experience and Preparedness for Sudden Death Conditions......79 


\section{LIST OF FIGURES}

Figure B1. WVSSAC Emergency Action Plan Worksheet - Student Response Team.........47

Figure B2. NCAA Heat-Acclimatization Guidelines...................................57

Figure B3. Prevention of Exertional Hyponatremia with Recommended Fluid Intake Strategy..58 


\section{INTRODUCTION}

Coaches in the secondary school setting may be obligated to complete responsibilities that extend further than coaching responsibilities. ${ }^{1-6}$ Responsibilities may include medical coverage for student athletes especially in rural or low-income school districts. ${ }^{1,3-5,7-9}$ Although secondary school coaches are required to be certified in cardiopulmonary resuscitation (CPR), automated external defibrillator (AED) use and first aid, conditions which constitute a medical emergency may not be known. Although coaches are responsible for the wellbeing of the athletes, proper education may not be apparent for medical emergencies. ${ }^{1,2,5,8,10}$

Many medical emergencies that coaches encounter are musculoskeletal injuries but sudden death conditions in athletes are common and pose a threat to the health of athletes. ${ }^{3}$ Coaches may not understand how to recognize the conditions' signs and symptoms or when to remove the athlete from participation, or when to activate an emergency action plan (EAP). The coaches may also not be aware of the EAP which is designed to be activated in the event of a medical emergency. The lack of comprehension for medical emergencies by coaches has led to the creation of educational opportunities on athletic injuries and are required in select states. ${ }^{8}$

The state of West Virginia requires any prospective coach that are not teachers within the West Virginia Department of Education (WVDE) to complete the West Virginia Secondary School Activities Commission (WVSSAC) Coaches Education Course. ${ }^{11}$ The course is completed in 14 hours and includes a Sports First Aid Course. ${ }^{11}$ If the coach is a WVDE teacher, the Coaches Education course is not required. However, both the WVDE and non-WVDE coaches are required each year to complete the "Concussion in Sport," "Heat Illness Prevention," and "Sudden Cardiac Arrest" courses provided by the National Federation of State High School Association (NFHS). ${ }^{11-14}$ 
Medical emergencies in secondary school athletics pose a risk of catastrophic injury or sudden death. The National Athletic Trainers' Association developed a position statement that categorized sudden death in athletes into ten conditions: asthma, catastrophic brain injuries, cervical spine injuries, diabetes, exertional heat stroke, exertional hyponatremia, exertional sickling, head-down contact in football, lightning, and sudden cardiac arrest. ${ }^{15-17}$ Health care professionals such as athletic trainers are educated in sudden death conditions. ${ }^{1,15,16,18}$ Because of this, recommendations for athletic trainers and those in the athletic population have been established regarding the previously listed conditions. ${ }^{15-17,19,20}$ What is cause for concern is that coaches may not be aware of the conditions nor if the treatment if a health care professional is not available.

Studies $^{1,2,21,22}$ on sudden death in sport have researched the coaches' certification in First Aid/CPR/AED and suggested that coaches are more confident during medical emergencies if certified. Despite the benefit of coaches who are certified in First Aid/CPR/AED use, it is recommended that an athletic trainer should be present for all athletic events. ${ }^{2,15-17,21,23,24}$ It is also recommended that an EAP should be developed for school athletic programs. ${ }^{15-17,20,21,24-26}$ The EAP for athletics should be site-specific, be coordinated with staff members and local emergency medical services, and be rehearsed annually. ${ }^{10,15,17,20,26,27}$ In West Virginia, the WVSSAC requires the completion of the "Emergency Action Plan Worksheet - Student Response Team." ${ }^{12,13}$ Lastly, an athletic trainer is required to be present for all high school football practices and games but not mandatory for other WVSSAC organized sports. ${ }^{28}$ If an athletic trainer cannot be hired, the school can hire a "Limited Football Trainer" who is a licensed health care professional (physician, registered nurse, licensed practical nurse, chiropractor, physical 
therapist, occupational therapist, physician's assistant, paramedic, or emergency medical technician) to provide care for football. ${ }^{28}$

If the athletic program does not provide an athletic trainer or other licensed health care professional, the responsibility for medical coverage falls to the coach. ${ }^{6}$ While some coaches may be educated in handling injuries associated with athletics, they may not be properly equipped for a sudden death situation. Since a study has not been conducted on the emergency preparedness for sudden death in secondary school athletics in the state of West Virginia, there is need for this study, especially if a health care professional is not available. The purpose of this study is to determine if WVSSAC coaches are aware and prepared to handle sudden death conditions in secondary school athletics whether an athletic trainer is present or not, and to determine the availability and use of an EAP for athletics.

\section{METHODS}

Design

This was a prospective exploratory study that reported results collected from a 16-item online questionnaire. The participants answered demographic information and questions relating to the sport(s) the participants coach in West Virginia secondary schools. Also evaluated was the awareness, preparedness, and previous provision of care of coaches for sudden death conditions in secondary school student-athletes with possible activation of the EAP. The health care provider for the secondary school was determined. Lastly, the use of an EAP for the sudden death condition situations was evaluated.

\section{Participants}

The participants of this study were WVSSAC secondary school coaches who provided the WVSSAC with an e-mail address. The potential number of participants included the 
approximately 2,000 members of the WVSSAC. Of those 2,000 members, 228 participants completed and returned the questionnaire for a return rate of $10 \%$. Additional inclusion criteria included being a member of the WVSSAC, previously taken the WVSSAC Coaches Course, or a WVDE teacher who coaches. The participants that were excluded from this study were any coaches who are not members of the WVSSAC, under the age of 18 , and those who do not fit the inclusion criteria. The acknowledgement of this study is on file from this Institution's Office of Research Compliance.

Instrument

The questionnaire was developed following a review of literature of previous evidencebased research by inspecting questions and other questionnaires. ${ }^{2,22}$ The focus of the questionnaire was to determine the coaches' level of awareness, preparedness, and provision of care of sudden death situations in student-athletes, health care provider, and the availability of an EAP. The questionnaire contained 16 questions. The questions in the questionnaire consisted of EAP availability, coaches' awareness, preparedness, and provision of care, demographics, whether the coach is certified in first aid/CPR and completed the three NFHS courses, sport(s) the participants coach, and the health care provider for the school.

The EAP section consisted of 2 forced choice questions identifing whether the school the coach is currently working at has an EAP for athletics and if the school completed the WVSSAC "Emergency Action Plan Worksheet - Student Response Team" worksheet. The sudden death situation experience section was comprised of 3 forced choice selections listing the sudden death conditions as cited by the NATA. The three questions included awareness, preparedness, and previous provision of care for each sudden death condition. Within the provision of care 
question, the participant could select if the EAP was activated for the specific sudden death condition.

The demographic portion of the questionnaire was composed of 9 forced choice and 4 multiple selection questions including gender, highest level of education completed, paid occupation, years coaching overall, years coaching in the secondary school setting, and classification of the high school that the participant currently coaches at. The First Aid/CPR section consisted of whether the coach is certified in First Aid/CPR/AED use, has completed the WVSSAC Coaching Course, and whether the coach completed the online NFHS courses in concussion, heat illness, and sudden cardiac arrest recognition. Lastly, participants were asked who the health care provider is for the school.

The questionnaire was reviewed by classmates for readability and clarity prior to distribution. A psychometric analyst who is experienced in research, questionnaires, and surveys assisted in developing the survey and reviewed for content and face validity.

Procedures

The participants were coaches who completed the e-mailed questionnaire through the WVSSAC. The e-mail included a brief description of the questionnaire with the cover letter (Table $\mathrm{C} 1$ ) that contained the link to the questionnaire and explained the procedures of the questionnaire, directions with each part of the questionnaire should the participant be willing to participate, and the rights of the participant. Upon clicking on the link, the participant was redirected to Qualtrics. Immediately after, participants were questioned to select whether to continue to the survey (Table C2). A follow-up e-mail was sent via the WVSSAC to all participants approximately two weeks following the initial e-mail to WVSSAC secondary school 
coaches to further encourage participation (Table C3). The participants were contacted on

February 18, 2019. The questionnaire link was available for completion for three weeks in total.

Qualtrics recognizes “Confidential Information” as Terms, Orders, other agreements between the customer and Qualtrics, business and marketing plans and strategies, non-public business and technology information, trade secrets, Data, any written materials marked as confidential, and any other information, including visual and oral information, which reasonably should be understood to be confidential. The customer and Qualtrics will use commercially reasonable efforts, including appropriate technology and industry practices, to ensure the confidentiality, integrity, and security of all Confidential Information. To the extent allowed by law, the author agrees to indemnify and hold Qualtrics, and if applicable, the licensors and affiliates and each of their officers, directors, employees, and agents harmless against any and all claims and expenses, including reasonable attorneys' fees, arising from the use of the Services. This indemnification expressly includes the authors responsibility for any and all liability arising from the violation or infringement of copyrights, trademarks, or other proprietary rights and from the use of any libelous or unlawful material contained within the authors Data. ${ }^{29}$

Qualtrics' most important concern is the protection and reliability of Customer data. The Qualtrics servers are protected by high-end firewall systems, and scans are performed regularly to ensure that any vulnerabilities are quickly found and patched. Complete penetration tests are performed yearly. All services have quick failover points and redundant hardware, with complete backups performed nightly. Qualtrics uses Transport Layer Security (TLS) encryption (also known as HTTPS) for all transmitted data. Surveys may be protected with passwords and HTTP referrer checking. The 
Qualtrics services are hosted by trusted data centers that are independently audited using the industry standard SSAE-16 method. ${ }^{30}$

\section{Statistical Analysis}

Descriptive statistics were conducted, which included means, frequencies, and standard deviations. Pearson Chi Squares were performed to determine likelihood of demonstrating common themes of preparedness of WVSSAC coaches regarding sudden death conditions, health care provider, and the availability of an EAP. The comparisons that were evaluated included whether the WVSSAC Coaching Course better prepares coaches for sudden death situations more than WVDE coaches, if the coaches are better prepared with an athletic trainer or not, and the comparison between having an athletic trainer or not regarding the availability of an EAP. Independent variables included the health care provider and the WVSSAC coaching course. Dependent variable was the preparedness of coaches regarding sudden death conditions and availability of an EAP. A P-value of $\mathrm{P}=0.05$ was used for all analysis. All statistical analyses were performed utilizing IMB-SPSS Version 24.0 for Windows (IBM-SPSS, Chicago, IL.).

\section{RESULTS}

Demographic

There were 288 total responses submitted through Qualtrics. Of those responses, 60 were removed from the data due to incompleteness of the questionnaire. The estimated response rate was $10 \%$. There were more males $(61.8 \%, \mathrm{n}=141)$ who completed the survey as compared to females $(33.8 \%, \mathrm{n}=77)$. Half of all completed questionnaires reported highest level of education to be a graduate degree $(50.0 \%, \mathrm{n}=114)$ and one-third completed a Bachelor's degree $(32.5 \%$, $\mathrm{n}=47$ ). West Virginia Department of Education (WVDE) teachers comprised over half of the coaches $(61.8 \%, \mathrm{n}=141)$ compared to coaches who's paid occupation was not as a teacher within the WVDE schools $(33.8 \%, \mathrm{n}=77)$. Coaches responded an even distribution of total years 
coaching as well as specifically at the high school level. See Table D2 and D3 for additional information.

Of the respondents, there was an even distribution of coaches between the three WVSSAC high school classifications based on student population size: "A" $(29.4 \%, n=67)$, "AA" $(35.5 \%, n=81)$, and "AAA" $(27.2 \%, n=62)$. Coaches responded to what sports they coached as a head, assistant, or volunteer position of the listed WVSSAC sports, the highest being head track and field $(12.3 \%, \mathrm{n}=28)$, head basketball $(10.5 \%, \mathrm{n}=24)$, head soccer $(10.1 \%$, $\mathrm{n}=23)$, and head football coaches $(9.6 \%, \mathrm{n}=22)$. See Table D4 for additional results. Over half of all coaches reported they were First Aid/CPR/AED certified $(56.1 \%, \mathrm{n}=128)$. Nearly 60\% $(59.6 \%, \mathrm{n}=136)$ responded they had taken the WVSSAC Coaching Course and nearly $90 \%$ $(89.0 \%, \mathrm{n}=203)$ reported they had taken the online NFHS Concussion, Heat Illness, and Sudden Cardiac Arrest within the last twelve months. Lastly, coaches reported that certified athletic trainers $(57.5 \%, \mathrm{n}=131)$ were the health care providers for secondary school athletics for the majority of respondents. See Table D5 and D6 for additional coaching certifications and health care provider information.

Coaches' Awareness and Preparedness of Sudden Death Conditions

Of the ten sudden death conditions, coaches reported the highest numbers for awareness for exertional heat stroke $(96.1 \%, \mathrm{n}=219)$, sudden cardiac arrest $(94.7 \%, \mathrm{n}=216)$, lightning (93.4\%, $\mathrm{n}=213)$, and asthma $(90.4 \%, \mathrm{n}=206)$. Exertional sickling was the condition of lowest awareness evenly selected with responses of being aware $(46.9 \%, \mathrm{n}=107)$ and unaware $(47.8 \%$, $\mathrm{n}=109$ ). The other five conditions for coaches' awareness are found in Table D7.

Coaches responded if they were prepared to handle sudden death conditions with the numbers consistently lower than awareness. The most prepared conditions for preparedness 
included exertional heat stroke $(90.8 \%, \mathrm{n}=207)$, sudden cardiac arrest $(87.3 \%, \mathrm{n}=199)$, asthma (83.3\%, $\mathrm{n}=190)$, and lightning $(77.6 \%, \mathrm{n}=177)$. Exertional hyponatremia $(52.2 \%, \mathrm{n}=119)$ had the lowest preparedness compared to awareness in the previous question. Also, exertional sickling $(\mathrm{n}=39.0 \%, \mathrm{n}=89)$ preparedness results continued to drop when asked if coaches were prepared to handle the situation, as more were unprepared $(52.6 \%, n=120)$ than prepared. Of the results reported, excluding exertional sickling, coaches felt more prepared than unprepared for handling nine of the ten sudden death conditions. See Table D8 for additional results.

\section{Emergency Action Plan (EAP)}

Of the responses, nearly all coaches $(97.8 \%, \mathrm{n}=223)$ reported an EAP for secondary school athletics. With further questioning, coaches cited that the majority $(93.4 \%, \mathrm{n}=213)$ had completed the "Emergency Action Plan Worksheet - Student Response Team" that was provided by the WVSSAC. While required to be uploaded to the WVSSAC website, only $6 \%(6.1 \%$, $\mathrm{n}=14$ ) reported it was not completed.

The coaches were asked if they had provided care for an athlete suffering from any of the sudden death conditions as well as to list if they had activated the EAP for the sudden death situation. While the majority of coaches reported no, asthma $(19.3 \%, \mathrm{n}=44)$, diabetes $(11.8 \%$, $\mathrm{n}=27)$, lightning $(9.6 \%, \mathrm{n}=22)$, and head-down contact in football $(8.8 \%, \mathrm{n}=20)$ were the greatest frequencies of conditions that required care from the coaches. However, the greatest number of EAP activations were for lightning $(6.6 \%, \mathrm{n}=15)$, head-down contact in football $(5.7 \%, \mathrm{n}=13)$, exertional heat stroke $(5.3 \%, \mathrm{n}=12)$, and cervical spine injuries $(4.8 \%, \mathrm{n}=11)$. All conditions were selected at least twice that care had to be provided and all conditions required the EAP to be activated at least three times. Additional results can be viewed in Table D9. 


\section{Health Care Provider}

Coaches were polled to determine the health care provider for secondary school athletics. If a school was unable to hire an athletic trainer for football practices and games, a limited football trainer may be hired who is a licensed health care professional. ${ }^{28}$ Choices the participants could select included certified athletic trainers as well as all of the possible limited football trainers. Certified athletic trainers $(57.5 \%, \mathrm{n}=131)$ were cited frequently as the health care provider. About $10 \%$ of coaches reported emergency medical technicians (EMT) $(9.2 \%, \mathrm{n}=21)$ and "None" $(9.2 \%, n=21)$ were the health care providers for the school. Physicians $(7.9 \%, n=18)$ and registered nurses $(7.5 \%, \mathrm{n}=17)$ were also listed as health care providers for about $8 \%$ of secondary schools. Refer to Table D6 for additional results.

The relationship between health care providers and the availability of the EAP was evaluated. Coaches with certified athletic trainers $(63.5 \%, n=129)$ reported over half had EAPs available and completed. When an EAP was not available, a certified athletic trainer was the health care provider $(1.0 \%, \mathrm{n}=2)$. See Table D10 to view additional results.

Relationships were also evaluated between health care providers and coaches' preparedness to provide care for all ten sudden death conditions. For all conditions, coaches with a certified athletic trainer as the health care provider believed to be more prepared to handle the condition than the other providers. With exertional sickling, coaches were less prepared no matter which health care providers were present. When athletic trainers were present, $32 \%$ $(n=62)$ of coaches were prepared to handle exertional sickling. See Table D11 through D20 for additional results. 


\section{Pearson Chi Squares}

Pearson Chi Squares were completed to determine relationships between health care providers and the availability of the EAP, health care providers and preparedness of coaches for sudden death conditions, and the WVSSAC Coaching Course and preparedness of coaches for sudden death conditions.

There was not a significant relationship between health care provider and the availability of the EAP $\left(\chi^{2}{ }_{1,228}=1.110, \mathrm{P}=0.999, \mathrm{cc}=0.074\right)$. There was a significant relationship between the health care provider and coaches' preparedness to provider care for asthma $\left(\chi^{2}{ }_{1,228}=23.621\right.$, $\mathrm{P}=0.005, \mathrm{cc}=0.327$ ). There was no significant relationship between the health care provider and coaches' preparedness for catastrophic brain injuries $\left(\chi^{2}{ }_{1,228}=10.886, \mathrm{P}=0.284, \mathrm{cc}=0.230\right)$, cervical spine injuries $\left(\chi_{1,228}^{2}=5.002, \mathrm{P}=0.834, \mathrm{cc}=0.158\right)$, diabetes $\left(\chi^{2}{ }_{1,228}=12.223, \mathrm{P}=0.201\right.$, $\mathrm{cc}=0.243)$, exertional heat stroke $\left(\chi_{1,228}^{2}=7.672, \mathrm{P}=0.568, \mathrm{c}=0.192\right)$, exertional hyponatremia $(\chi$ $\left.{ }_{1,228}=8.981, \mathrm{P}=0.439, \mathrm{cc}=0.211\right)$, or exertional sickling $\left(\chi^{2}{ }_{1,228}=10.769, \mathrm{P}=0.292, \mathrm{c}=0.230\right)$. However, there was a significant relationship between health care provider and preparedness for head-down contact in football $\left(\chi^{2}{ }_{1,228}=20.901, \mathrm{P}=0.013, \mathrm{cc}=0.312\right)$. There was also no significant relationship between health care provider and coaches' preparedness for lightning $(\chi$ $\left.{ }_{1,228}=9.683, \mathrm{P}=0.377, \mathrm{cc}=0.216\right)$ or sudden cardiac arrest $\left(\chi_{1,228}^{2}=7.634, \mathrm{P}=0.571, \mathrm{cc}=0.194\right)$.

The relationship between the WVSSAC Coaching Course and preparedness of coaches for sudden death conditions was examined. There was no significant relationship for any of the ten conditions including asthma $\left(\chi^{2}{ }_{1,228}=1.989, \mathrm{P}=0.158, \mathrm{cc}=0.099\right)$, catastrophic brain injuries $\left(\chi^{2} 1,228=3.420, \mathrm{P}=0.065, \mathrm{cc}=0.130\right)$, cervical spine injuries $\left(\chi^{2}{ }_{1,228}=3.352, \mathrm{P}=0.067, \mathrm{cc}=0.128\right)$, diabetes $\left(\chi_{1,228}^{2}=0.015, \mathrm{P}=0.903\right.$, $\left.\mathrm{cc}=0.009\right)$, exertional heat stroke $\left(\chi^{2}{ }_{1,228}=0.134, \mathrm{P}=0.715\right.$, $\mathrm{cc}=0.026)$, exertional hyponatremia $\left(\chi^{2} 1,228=2.757, \mathrm{P}=0.097, \mathrm{c}=0.117\right)$, exertional sickling $\left(\chi^{2} 1\right.$, 
$228=0.778, \mathrm{P}=0.378, \mathrm{cc}=0.063)$, head-down contact in football $\left(\chi^{2}{ }_{1,228}=1.332, \mathrm{P}=0.248\right.$, $\mathrm{cc}=0.082)$, lightning $\left(\chi^{2} 1,228=1.335, \mathrm{P}=0.248, \mathrm{cc}=0.081\right)$, or sudden cardiac arrest $\left(\chi^{2}{ }_{1,228}=1.639\right.$, $\mathrm{P}=0.200, \mathrm{cc}=0.090$ ). However, for all conditions except exertional sickling, coaches who completed the WVSSAC Coaching Course felt more prepared to handle the sudden death condition. Refer to Table D21 for additional results.

Fisher's Exact Test

Fisher's Exact Tests were completed to determine the relationship between the completion of the annual three NFHS courses and preparedness of coaches for sudden death conditions as well as years of coaching experience and preparedness of coaches. Pearson Chi Squares could not be run due to less than five data entries in more than one of the cells. Additionally, both Fisher's Exact Tests were two-sided tests. The relationship between the NFHS course completion and sudden death preparedness of coaches was examined. There was no significant relationship between any condition including asthma $(\Sigma=0.327, \mathrm{P}=1.000)$, catastrophic brain injuries $(\Sigma=1.149, \mathrm{P}=0.775)$, cervical spine injuries $(\Sigma=0.991, \mathrm{P}=0.768)$, diabetes $(\Sigma=0.523, \mathrm{P}=1.000)$, exertional heat stroke $(\Sigma=0.905, \mathrm{P}=1.000)$, exertional hyponatremia $(\Sigma=1.334, \mathrm{P}=0.683)$, exertional sickling $(\Sigma=2.600, \mathrm{P}=0.332)$, head-down contact in football $(\Sigma=1.164, \mathrm{P}=0.594)$, lightning $(\Sigma=0.343, \mathrm{P}=1.000)$, or sudden cardiac arrest $(\Sigma$ $=0.564, \mathrm{P}=1.000)$. Despite the lack of significant relationships, coaches who completed the three NFHS courses reported more prepared to provide care for nine of ten sudden death conditions. See Table D22 for additional results.

Lastly, the relationship between years of coaching experience and preparedness for sudden death conditions was examined with Fisher's Exact Test. There was not a significant relationship between years of coaching and all ten sudden death conditions that included asthma 
( $\Sigma=4.235, \mathrm{P}=0.370)$, catastrophic brain injuries $(\Sigma=2.337, \mathrm{P}=0.681)$, cervical spine injuries $(\Sigma$ $=3.271, \mathrm{P}=0.515)$, diabetes $(\Sigma=2.087, \mathrm{P}=0.729)$, exertional heat stroke $(\Sigma=4.065, \mathrm{P}=0.369)$, exertional hyponatremia $(\Sigma=2.651, \mathrm{P}=0.622)$, exertional sickling $(\Sigma=3.272, \mathrm{P}=0.520)$, headdown contact in football $(\Sigma=0.701, \mathrm{P}=0.957)$, lightning $(\Sigma=8.312, \mathrm{P}=0.076)$, and sudden cardiac arrest $(\Sigma=7.590, \mathrm{P}=0.081)$. Refer to Table $\mathrm{D} 23$ for additional results.

\section{DISCUSSION}

The purpose of this study was to determine West Virginia secondary school coaches' awareness and preparedness for sudden death conditions and the availability of an EAP. Coaches responded to an online questionnaire to determine whether they were aware of, prepared to, and have provided care for a sudden death emergency for athletes. Other questions asked about the EAP for athletics in the secondary school and the health care provider for athletics.

The results of this questionnaire emphasized that coaches were aware of all ten conditions listed as sudden death conditions in athletics and prepared to handle nine of the conditions. However, preparedness frequencies were lower than awareness for all ten conditions. Exertional heat stroke was consistently listed as the condition the coaches were more aware and prepared for. Asthma and diabetes were the highest percentages of conditions that coaches provided care for an athlete previously. All conditions required coaches to provide care to an athlete as well as to activate the EAP. Nearly all coaches reported an EAP for athletics and the majority indicated the school completed the "Emergency Action Plan Worksheet - Student Response Team." The most commonly cited health care provider for secondary school athletics was a certified athletic trainer, EMT, and "None."

There was no relationship between health care provider and the availability of the EAP. However, half of the coaches reported a certified athletic trainer as the health care provider and 
had completed the EAP for athletics. Relationships were demonstrated between health care provider and two sudden death conditions: asthma and head-down contact in football. Since high school football in the state of West Virginia is required to have a health care provider, this emphasizes the importance of a designated health care provider. There were no relationships between the other eight sudden death conditions and health care providers. Despite no significant results for those conditions, coaches with an athletic trainer reported the highest preparedness frequencies compared to all other health care providers. No relationship was demonstrated between the WVSSAC Coaching Course completion and coaches' preparedness for the all sudden death conditions. Despite coaches reporting the WVSSAC Coaching Course felt more prepared for nine conditions, there was no statistically significant results. Additionally, there were no statistically significant results between the relationship between completion of NFHS courses and coaches' preparedness nor between years of coaching experience and preparedness for sudden death conditions. However, coaches who completed the NFHS courses felt more prepared to handle nine conditions more than coaches who did not complete the course.

The majority of the hypotheses were accepted. The first hypothesis stated $75 \%$ of coaches were First Aid/CPR/AED certified and has been rejected with $56.1 \%$ of participants with the certification. The second hypothesis stated $50 \%$ of coaches paid occupation would be a teacher within the WVDE. This hypothesis has been accepted, $61.8 \%$ were teachers hired through the WVDE. The third hypothesis stated $75 \%$ of coaches have completed the NFHS courses within twelve months and has been accepted as $89.0 \%$ of respondents completed the courses. The fourth hypothesis stated $50 \%$ of coaches reported an athletic trainer as the health care provider for the school. This hypothesis has been accepted as $57.5 \%$ of participant reported a certified athletic trainer as the health care provider. The fifth hypothesis stated 50\% of the coaches will report a 
non-athletic trainer as the health care provider. This hypothesis has been rejected since $49.6 \%$ of participants reported a non-athletic trainer as the health care provider of the school. The sixth hypothesis stated $75 \%$ of coaches are prepared to provide care for asthma, catastrophic brain injuries, cervical spine injuries, diabetes mellitus, exertional heat stroke, head-down contact in football, and lightning. This hypothesis has been rejected as catastrophic brain injuries (66.7\%), cervical spine injuries $(68.0 \%)$, and head-down contact in football $(65.4 \%)$ did not meet the criteria. However, since asthma (83.3\%), diabetes (75.9\%), exertional heat stroke (90.8\%), and lightning (77.6\%) met the criteria, this could partially be accepted. The seventh hypothesis stated $25 \%$ of coaches are prepared to provide care for exertional hyponatremia and exertional sickling. This hypothesis has been accepted with both exertional hyponatremia and exertional sickling with frequencies of $52.2 \%$ and $39.0 \%$, respectively. The eighth hypothesis stated $50 \%$ of coaches are prepared to provide care for sudden cardiac arrest which has been accepted with $77.6 \%$ of participants reported being prepared to provide care. The ninth and last hypothesis stated $75 \%$ of coaches will report an EAP for athletics. This hypothesis has been accepted, as $97.8 \%$ of participants reported an EAP for athletics.

Emergency Action Plan

If a medical emergency occurs, a written EAP is used to contact the proper authorities to increase survival rates. The written document provides instructions and information for the management of emergencies. ${ }^{26}$ It is recommended to be coordinated with on-site responders and emergency medical services, distributed to all athletic staff members, and identify on-site emergency equipment such as an AED. ${ }^{20,26,31}$ In West Virginia, the WVSSAC requires every sport at each school to complete and upload an "Emergency Action Plan Worksheet - Student Response Team."12,13 The document includes a 911 Team, CPR/AED Team, AED Team, and 
Heat Stroke Team. ${ }^{13}$ While the EAP - Student Response Team is designed for the absence of an on-site health care professional, it does not include vital information which is deemed necessary for EAPs. Twenty-four state athletic associations (47\%) within the United States of America recommend developing an EAP. ${ }^{20}$ Valovich McLeod et al ${ }^{32}$ reported 95\% of Arizona secondary school athletic directors had a written EAP and 93\% had an AED available at the school. Specifically, the study also reported the athletic directors were aware of the Arizona interscholastic concussion policy, had a school-specific concussion policy (98\%), and familiar with the state heat-illness policy $(99 \%) \cdot{ }^{32}$ Lastly, if the secondary school had access to an athletic trainer, the school was more likely to have an EAP available, a venue-specific EAP, physician approval of the EAP, AEDs available, heat illness policies, and cold-water immersion tubs. ${ }^{32}$

Of the coaches surveyed in this questionnaire, nearly all (97.8\%) reported the availability of an EAP for secondary school athletics. In addition, the majority of coaches had completed the "Emergency Action Plan Worksheet - Student Response Team" for the respective schools. The WVSSAC requires the "Emergency Action Plan Worksheet - Student Response Team" to be completed and uploaded by every sport each year. ${ }^{13}$ Adams et $\mathrm{al}^{20}$ reported that there were no state requirements for the EAP in the state of West Virginia which is noteworthy that nearly all coaches had some form of EAP. However, the Korey Stringer Institute ${ }^{12}$ stated that all schools or organizations that offers athletics in West Virginia should develop an EAP for athletics. The Korey-Stringer Institute may have assumed the "Emergency Action Plan Worksheet - Student Response Team" to be used as the EAP for athletics while Adams et $\mathrm{al}^{20}$ may not have. Furthermore, Schneider et $\mathrm{al}^{1}$ reported $38 \%$ of West Virginia schools possessed a published EAP for athletics. However, the participants of the fore mentioned study were West Virginia public high school principles (92\%) and athletic administrators (8\%). ${ }^{1}$ As the results from this 
questionnaire showed nearly all coaches reported an EAP for athletics, it can be surmised that coaches are aware of the importance of the document and the health and safety of athletes compared to administrators.

Coaches responded that all ten sudden death conditions required the EAP to be activated at least twice. Despite coaches reporting provision of care for each sudden death condition, the majority of conditions did not require activation the EAP. However, if a situation when an athlete experienced the sudden death condition, the EAP was activated. The most common conditions which required coaches to provide care included asthma and diabetes. As both conditions affect 25-30 million Americans, it is commonly observed in athletics. ${ }^{33-36}$ There were seven high school and college football fatalities associated with asthma complications from 1990-2010. ${ }^{37}$ Also, 228 diabetes-related deaths occurred from 2012-2014 in persons under the age of $19 .{ }^{38}$ It was also reported that the EAP was activated when the coach did not provide care. This study did not question who activated the EAP.

The relationship between the health care provider and the availability of the EAP was assessed. There was no significant relationship reported, however the majority of coaches reported an athletic trainer as the provider with an EAP available. It is suggested in the literature $\mathrm{e}^{1,2,15,16,20,39}$ that the EAP should be developed with local emergency medical services, school safety officials, on-site medical personnel, and school administrators and include health care professionals who provide medical coverage.

Coaches' Awareness, Preparedness, and Provision of Care

Awareness of sudden death conditions were reported. Coaches were aware of nine of the ten conditions. Coaches were also prepared to handle the same nine of the ten conditions despite demonstrating lower frequencies. The highest frequency for awareness and preparedness was for 
exertional heat stroke. It is commonly portrayed in the media and part of the required NFHS Heat Illness course. ${ }^{13,40-42}$ Thirty-eight heat-related deaths occurred from 1990-2010 in high school and college football players, many of which were highly publicized. ${ }^{37}$ Also, football practice lengths and rates are regulated in West Virginia which is related to a gradual acclimatization period to prevent heat stroke..$^{10,17,41,43,44}$ Additionally, sudden cardiac arrest was cited as the second highest frequency for awareness $(94.7 \%)$ and preparedness $(87.3 \%)$. With a NCAA incidence rate of 1:43,000 annually, sudden cardiac arrest is the leading cause of exercise-related death in young athletes and necessary for coaches to recognize and provide care. ${ }^{45,46}$ A NFHS course in Sudden Cardiac Arrest is also required for West Virginia secondary school coaches. ${ }^{13,42}$

Coaches reported provision of care for all ten sudden death conditions with most experience with asthma (19.3\%) and diabetes (11.8\%). Asthma affects an estimated 25 million people in the United States. ${ }^{15,35,36,47}$ Participants in this study reported frequencies of feeling more aware than prepared, at $90.4 \%$ to $83.3 \%$, respectively. As rates of health risk and chronic diseases are increasing, West Virginia high school athletes can be at greater risk of a sudden death incident from genetics or past medical history. ${ }^{1,48}$

Catastrophic brain injuries were noted to have high awareness frequencies at $88.2 \%$ compared to preparedness at $66.7 \%$. It is surmised that since coaches take the NFHS “Concussion In Sport” course on a yearly basis, awareness and preparedness may have been more evident. But with $45 \%$ of traumatic brain injuries that happened in contact sports referred to the emergency department, ${ }^{49}$ most coaches would refer than treat. As contact sports are common in West Virginia, it can be assumed that coaches refer athletes to emergency departments because of a lack of health care provider. In West Virginia, if a concussion is 
suspected, athletes cannot return to sport until cleared by a doctor of medicine, certified athletic trainer, physician's assistant, or advanced practice registered nurse. ${ }^{12,14}$ If a previously listed health care professional is not the health care provider for the school, coaches should be referring athletes to an emergency department. A very low number of coaches did report providing care for athletes suffering from catastrophic brain injuries but the EAP was activated only $3.5 \%$ of the time. As this number may include concussions which did not exhibit red flags, coaches may have held athletes from participation without the immediate need for emergency medical services.

Cervical spine injuries occurring from sport are estimated in 960 athletes annually. ${ }^{50}$ Coaches self-reported to be more aware $(83.3 \%)$ than prepared $(68.0 \%)$ to provide care. However, $5.3 \%$ of coaches provided care and $4.8 \%$ activated the EAP for a cervical spine injury. Due to serious health complications that arise from cervical spine injuries such as breathing control issues or quadriplegia, coaches should activate the EAP for any athlete complaining of midline spine pain, neurological complaints, altered level of consciousness, or deformity. ${ }^{50-54}$

Type I diabetes-related awareness and preparedness was the second highest condition which coaches were required to provide care $(11.8 \%)$ but with lower frequencies of activation of the EAP (1.8\%). There were 228 diabetes-related deaths under the age of 19 from 2012-2014. ${ }^{38}$ With high fatality numbers in the same population the participants work with, this condition's signs and symptoms should be made aware.

Exertional hyponatremia was a sudden death condition coaches were aware of (58.8\%) and prepared for $(52.2 \%)$ but reported provision of care to be minimal (0.9\%). As this condition is commonly seen in high endurance competitions, West Virginia secondary school coaches may not experience exertional hyponatremia. ${ }^{55,56}$ However, since athletes may be required to record 
body weights on weight charts before and after practice, early stages of hyponatremia may be addressed prior to severe symptoms and the need for EAP activation.

The lowest awareness and preparedness for a sudden death condition was exertional sickling. Coaches reported they were not aware (46.6\%) and not prepared (39.0\%) to provide care for this condition. Additionally, exertional sickling did not require care often (0.9\%) from coaches but did warrant EAP activation (2.2\%) at times. Athletes who experience exertional sickling carry the sickle cell trait and common in African, Mediterranean, Middle Eastern, or Caribbean ancestry. ${ }^{17,57-59}$ According to the United States Census Bureau, ${ }^{60} 4.4 \%$ of the current West Virginia population are of the previously listed nationalities. Since the population rates are low, the risk of sickle cell trait is also low as coaches may not experience an athlete with the trait and moreover exertional sickling.

Coaches reported head-down contact in football awareness rates (78.9\%) were higher than preparedness (65.4\%). Also, 8.8\% of coaches provided care and 5.7\% activated the EAP for a situation with head-down contact in football. With 1.1 million high school football athletes annually, the risk of injuries or fatalities associated is high. ${ }^{61}$ It should be noted that all coaches were asked this question and not only football coaches. Some coaches may not experience this condition due to sport assignment. However, since an athletic trainer or limited football trainer is required for football practices and games, coaches may feel more prepared to provide care for athletes who suffered injuries after head-down contact in football. ${ }^{28}$

Lightning was reported that coaches were more aware (94.7\%) than prepared (77.6\%). As the most dangerous natural hazard, it is often observed in daily living and 53\% of lightningrelated fatalities occurred during sporting activities. ${ }^{15,62,63}$ Participants responded care was provided for lightning-related injuries in $9.6 \%$ of coaches with the activation of the EAP in $6.6 \%$. 
Proper prevention strategies such as suspension of all outdoor athletic events when lightning is observed and thunder is heard can reduce the risk of lightning-related injuries. ${ }^{15,62,63}$ However, this condition was the greatest frequency $(6.6 \%)$ that coaches were required to activate the EAP. This is interesting since West Virginia is not considered a high lightning strike state compared to Southeast and Midwest States with the highest frequency of lightning strikes. ${ }^{62}$

When an athletic trainer was named the health care provider, coaches reported being more prepared to handle sudden death conditions. Consistently, all sudden death conditions preparedness was higher for athletic trainers than all other health care providers combined. Exertional heat stroke was reported to be the highest level of preparedness $(62.0 \%)$ for coaches with an athletic trainer. Also, while exertional sickling preparedness rates (32.2\%) were the lowest of all conditions, having an athletic trainer as the health care provider had a strong influence on coaches' preparedness.

Guidelines in West Virginia

Prerequisites to become a secondary school coach in West Virginia schools vary depending on vocation. If a prospective coach is a teacher within the WVDE, requirements include a certification in First Aid/CPR/AED use and the annual NFHS Courses in Concussion, Heat Illness, and Sudden Cardiac Arrest. For non-teachers, the individuals must complete the WVSSAC Coaching Course. ${ }^{11}$ The WVSSAC Coaching Course is comprised of Coaching Principles, Sports First Aid, and West Virginia Rules and Regulations. ${ }^{13}$ Once completed the course, the prospective coaches must complete three online examinations with a score of $80 \%$ or higher. ${ }^{13}$ Of the respondents, $60 \%$ reported their paid occupation was a teacher in the WVDE. Surprisingly, nearly the same frequency of coaches reported completion of the WVSSAC Coaching Course. Despite more coaches being teachers, over half of participants still finished the 
14-hour course. This may be due to coaches who began working within a sport prior to being hired as a teacher. Also, the WVSSAC Coaching Course qualifies for up to five college credits through West Virginia University. ${ }^{11}$ Prospective coaches may have completed the course while enrolled in college and later hired into the WVDE.

In West Virginia, the WVSSAC requires all coaches to become initially certified in First Aid/CPR/AED. ${ }^{1}$ The online NFHS Courses (Concussion, Heat Illness, and Sudden Cardiac Arrest) are required to be completed annually. ${ }^{11,14}$ Of the responses, $89 \%$ of coaches completed the NFHS courses within twelve months and only $56 \%$ are currently First Aid/CPR/AED certified. Schneider et $\mathrm{al}^{1}$ reported one-third of West Virginia high schools require maintenance of CPR/AED certification yet one-third do not require coaches to retain the certification.

Furthermore, coaches who completed the NFHS courses felt more prepared to provide care for an athlete for nine of ten sudden death condition.

Health care providers vary for secondary school athletics in West Virginia. The athletic trainer or limited football trainer is required for high school football only. Policy 5112 "Athletic Trainers in the Public Schools of West Virginia" ${ }^{28}$ states an athletic trainer or limited football trainer must be present for all senior high football practices, scrimmages, and games. If the hiring county board of education is unable to hire an athletic trainer, a limited football trainer may be employed who is a licensed health care professional such as physician, registered nurse, licensed practical nurse, chiropractor, physical therapist, occupational therapist, physician's assistant, paramedic, or emergency medical technician. ${ }^{28}$ Pryor et a ${ }^{10}$ reported in the state of West Virginia, $85 \%$ of public secondary schools reported athletic trainer services with $46 \%$ with a full time athletic trainer. ${ }^{10}$ It was reported athletic trainers were present for practice coverage daily for $67 \%$ of West Virginia schools. ${ }^{10}$ Additionally in the state of Arizona, it was reported that 
access to an athletic trainer increased the likelihood the secondary school would have venue specific and physician approved EAPs, access to AEDs and heat illness policies such as coldwater immersion tubs. ${ }^{32}$ Fifty-seven percent of participants cited an athletic trainer was the health care provider for secondary school athletics. "None" listed as the health care provider was the second highest response. Not listed as a health care provider was "State Certified AT" however it was listed under "Other.” Previously offered at universities in West Virginia, State Certified Athletic Trainers completed coursework to provide medical services but did not receive a certification from the Board of Certification or are recognized by the NATA. Despite the shift away from State Certified Athletic Trainers, the response could have been misconstrued and coaches may have listed "Certified Athletic Trainer" incorrectly.

Coaches' Preparedness for Sudden Death Conditions

Relationships were evaluated using Pearson Chi Squares between coaches' preparedness for sudden death conditions and the health care provider as well as the WVSSAC Coaching Course. The ten conditions were evaluated separately to every health care provider. Asthma and head-down contact in football were determined to be significant relationships when examining health care provider and coaches' preparedness. When evaluating these relationships, it can be presumed that coaches with athletic trainers as health care providers feel prepared to handle an asthma situation as well as provide care for an athlete who suffers a spinal fracture or cord damage after head-down contact in football.

While the other eight conditions did not find significant relationships, coaches with athletic trainers felt more prepared to handle an athlete suffering from all conditions than all other health care providers combined. Exertional sickling was the only condition in which coaches believed themselves to be unprepared than prepared with all health care providers. As 
asthma is a common chronic disease, coaches may understand the condition more than others based on previous experiences. Athletic trainers may also educate coaches on signs and symptoms an asthmatic athlete may experience to prevent the EAP to be activated. Also, as football is the only sport that requires a health care professional present, it can be construed that coaches feel prepared for sudden death situations because an educated professional will provide care especially for head-down contact in football. From these findings, athletic trainers can allow coaches to feel equipped for a sudden death situation.

The relationship between the WVSSAC Coaching Course and coaches' preparedness for sudden death conditions was examined. While there was no significant relationship between any of the ten conditions and the course, coaches reported the course better prepared them for nine of the ten conditions. The singular condition which did not represent that the course increased preparedness was for exertional sickling. Sickle cell trait, with risks such as exertional sickling, is not commonly exhibited in West Virginia. ${ }^{60}$ Coaches may not be aware of the condition let alone the deadly ramifications of improper identification. However, respondents of the questionnaire consistently answered to the remaining nine conditions that the WVSSAC coaching course better prepared them to care for an athlete. With the coursework and sports first aid section, coaches can provide life-saving care to athletes especially when a health care provider is not readily available.

Fisher's Exact Tests were performed to determine relationships between preparedness for sudden death conditions of coaches and NFHS course completion along with years of coaching experience. Similarly, coaches reported feeling more prepared for nine of ten conditions after completing the three online NFHS courses despite the lack of a statistically significant relationship. Exertional sickling was reported to be the only condition that more coaches who 
completed the courses did not feel prepared to handle. Completion of the NFHS courses can better prepare coaches for when sudden death conditions occur in athletics. The Korey Stringer Institute $^{64}$ suggested the annual completion of NFHS courses and to become certified by the NFHS in order to keep student athletes safe during athletics. Finally, the relationship between years of coaching experience and preparedness of coaches was examined with the use of a Fisher's Exact Test. Although there were no statistically significant results for all ten conditions, it can be inferred that coaches feel prepared to handle sudden death conditions regardless of years of coaching experience. There was a similar distribution of preparedness for all years of experience. Also, only exertional sickling was reported with more coaches feeling unprepared than prepared to provide care for sudden death conditions.

Clinical Implications

The results from this study suggested that West Virginia secondary school coaches' awareness and preparedness of sudden death conditions can be affected by an athletic trainer. Coaches steadily answered with better preparedness when an athletic trainer was present as the health care provider. Football requiring a health care professional at all exposures exhibited significant results when evaluating head-down contact in football. With an athletic trainer always present, coaches are prepared to handle the situation. This could indicate that requiring an athletic trainer for all West Virginia secondary school sports may increase preparedness results and ensure student-athlete safety.

The WVSSAC Coaching Course results led investigators to suggest that the course better prepares secondary school coaches to provide care for sudden death conditions. With the exception of exertional sickling, coaches reported the WVSSAC Coaching Course increased the preparedness of nine sudden death conditions. Mandating the course may ensure coaches to 
provide proper care for student-athletes. It may also assist coaches to anticipate medical emergencies such as the sudden death conditions examined in this study. Additionally, with much of the West Virginia population in a rural area, it is important for coaches to be prepared to handle an emergency until emergency medical services arrive. ${ }^{1}$ The coaches who are WVDE teachers should also be encouraged to complete the WVSSAC Coaching Course to become better prepared to handle medical emergencies. Also, all coaches should have continual maintenance of a First Aid/CPR/AED certification.

Based on responses of this questionnaire, nearly $90 \%$ of all coaches reported completing the three NFHS Courses within the previous twelve months. This study reported some of the highest frequencies of awareness and preparedness were of exertional heat stroke, sudden cardiac arrest, and catastrophic brain injuries. Since the coaches complete courses annually on those topics, the addition of other courses may be beneficial for student-athlete safety. Also, coaches who completed the NFHS courses reported higher levels of preparedness and could provide care for sudden death conditions. The results of this study indicated that the sudden death conditions of asthma and diabetes are the most common that coaches are required to provide care for. The addition of education for coaches for these two conditions may increase athlete survival rates as well as proper identification prior to a medical emergency. Lastly, exertional sickling and exertional hyponatremia information for best clinical practice for prevention, recognition, and treatment if it occurs in student athletes.

\section{Limitations}

The limitations of this study have been identified as phrasing of possible responses for the questionnaire such as certified athletic trainer being mistaken for State Certified Athletic Trainer. This survey was limited in response rate of participants to improve the strength of this 
study with a rate of $10 \%$. As this study was voluntary, coaches were not required to complete any or all of the questions. Additionally, West Virginia coaches were the only subjects included which may limit the study strength comparing to different states awareness and preparedness rates. Lastly, exertional sickling was a common question that coaches were unaware of that may have limited the results.

\section{CONCLUSION}

West Virginia secondary school coaches are aware and prepared to provide care for sudden death conditions in student-athletes. However, coaches continuously reported being more aware than prepared to handle all conditions. When athletic trainers were the health care provider, coaches were more prepared to handle all ten sudden death conditions compared to other health care providers. Lastly, coaches who have completed the WVSSAC Coaching Course showed higher preparedness frequencies for sudden death conditions compared to those who had not completed.

Athletic trainers present for practices and games increase the preparedness for coaches regarding sudden death conditions. The WVSSAC Coaching Course better prepared coaches to provide care for sudden death conditions in athletics. Finally, additional courses for asthma, diabetes, exertional sickling, and exertional hyponatremia could increase the awareness and preparedness of coaches through the NFHS or WVSSAC. 


\section{REFERENCES}

1. Schneider K, Meeteer W, Nolan JA, Campbell HD. Health care in high school athletics in West Virginia. Rural Remote Health. 2016:1-11.

2. Strand B, David S, Lyman KJ, Albrecht JM. Coaching in the United States: High school coaches' knowledge and confidence regarding athlete safety and injury management. Int Sport Coach J. 2017;4(2):220-234.

3. Faure CE, Pemberton CLA. An examination of Idaho high school football coaches' general understanding of concussion. Sport J. 2011;14(1):1-9.

4. Esquivel A, Haque S, Keating P, Marsh S, Lemos S. Concussion management, education, and return-to-play policies in high schools. Sports Health. 2013;5(3):258262.

5. Register-Mihalik J, Baugh C, Kroshus E, Y. Kerr Z, Valovich McLeod TC. A multifactorial approach to sport-related concussion prevention and education: Application of the socioecological framework. J Athl Train. 2017;53(3):195-205.

6. Mazerolle SM, Casa DJ, Pagnotta KD, Adams W, McGrath B, Fink J. The secondary school football coach's perspective of sudden death in sport. Applied Research in Coaching and Athletics Annual. 2014;29:84-120.

7. Carzoo SA, Young JA, Pommering TL, Cuff SC. An evaluation of secondary school educators' knowledge of academic concussion management before and after a didactic presentation. Athl Train Sport Heal Care. 2015;7(4):144-149.

8. Chrisman SP, Schiff MA, Chung SK, Herring SA, Rivara FP. Implementation of concussion legislation and extent of concussion education for athletes, parents, and coaches in Washington state. Am J Sports Med. 2014;42(5):1190-1196.

9. Pagnotta, KD, Mazerolle, SM, and Casa, DJ. Exertional heat stroke and emergency issues in high school sport. J Strength Cond Res. 2010;24(7):1707-1709.

10. Pryor RR, Casa DJ, Vandermark LW, et al. Athletic training services in public secondary schools: a benchmark study. J Athl Train. 2015;50:156-62.

11. Coach regulations WVSSAC rule 127-3-6. West Virginia Secondary School Actvities Comission. http://www.wvssac.org/coaches-education/coach-regulations/. Accessed October 17, 2018.

12. West Virginia High School Sports Safety Policies. Korey Stringer Institute. https://ksi.uconn.edu/high-school-state-policies-2/west-virginia/. Accessed March 27, 2019. 
13. West Virginia Secondary School Activities Commission. http://www.wvssac.org/. Accessed October 3, 2018.

14. 127-2-14. Concussion. West Virginia Secondary School Actvities Comission. http://www.wvssac.org/sports-medicine-news/. Accessed October 17, 2018.

15. Casa DJ, Guskiewicz KM, Anderson SA, et al. National athletic trainers' association position statement: Preventing sudden death in sports. J Athl Train. 2012;47(1):96118.

16. Casa DJ, Almquist J, Anderson SA, et al. The inter-association task force for preventing sudden death in secondary school athletics programs: Best-practices recommendations. J Athl Train. 2013;48(4):546-553.

17. Casa DJ, Anderson SA, Baker L, et al. The inter-association task force for preventing sudden death in collegiate conditioning sessions: Best practices recommendations. Strength Cond J. 2015;37(6):113-116.

18. Athletic Training. National Athletic Trainers' Association. https://www.nata.org/about/athletic-training. Accessed April 7, 2019.

19. Huggins RA, Scarneo SE, Casa DJ, et al. The inter-association task force document on emergency health and safety: Best-practice recommendations for youth sports leagues. J Athl Train. 2017;52(4):384-400.

20. Adams WM, Scarneo SE, Casa DJ. Assessment of evidence-based health and safety policies on sudden death and concussion management in secondary school athletics: A benchmark study. Orthop J Sport Med. 2018;53(8):756-767.

21. Johnson ST, Norcross MF, Bovbjerg VE, Hoffman MA, Chang E, Koester MC. Sports-related emergency preparedness in Oregon high schools. Sports Health. 2017;9(2):181-184.

22. Bly J, Meyer M, McGuire L, Meyer L. Examination of southwestern Pennsylvania high school athletic coaches level of knowledge and preceived preparedness of emergency care in athletics [Master's Thesis]. California, PA: California University Of Pennsylvania; 2015.

23. Katch RK, Scarneo SE, Adams WM, et al. Top 10 research questions related to preventing sudden death in sport and physical activity. Res Q Exerc Sport. 2017;88(3):251-268.

24. Pryor RR, Huggins RA, Casa DJ. Best practice recommendations for prevention of sudden death in secondary school athletes: An update. Pediatr Exerc Sci. 2014;26(2):124-126. 
25. Courson R. Preventing sudden death on the athletic field: The emergency action plan. Curr Sports Med Rep. 2007;6:93-100.

26. Andersen JC, Courson RW, Kleiner DK, McLoda TA. National athletic trainers' association position statement: Emergency planning in athletics. $J$ Athl Train. 2002;37(1):99-104.

27. Emergency Action Plans. Korey Stringer Institute. https://ksi.uconn.edu/prevention/emergency-action-plans/. Accessed March 27, 2019.

28. Title 126. Board of Education. https://wvde.state.wv.us/policies/p5112.pdf. Published 2011. Accessed June 11, 2018.

29. Terms of Service. Qualtrics. https://www.qualtrics.com/terms-of-service/. Revised: November 26, 2018. Accessed December 5, 2018.

30. Security Statement. Qualtrics. https://www.qualtrics.com/security-statement/. Published: July 13, 2018. Accessed December 5, 2018.

31. Adams WM, Scarneo SE, Casa DJ. State-level implementation of health and safety policies to prevent sudden death and catastrophic injuries within secondary school athletics. Orthop J Sport Med. 2017;5(9):1-8.

32. Valovich McLeod TC, Cardenas JF. Emergency preparedness of secondary school athletic programs in Arizona. J Athl Train. 2018;53(11):000-000.

33. Sports \& Recreation. American Diabetes Association. http://www.diabetes.org/livingwith-diabetes/parents-and-kids/everyday-life/sports-recreation.html. Accessed April 7, 2019.

34. Diabetes Home. Centers for Disease Control and Prevention.

https://www.cdc.gov/diabetes/basics/diabetes.html. Accessed April 7, 2019.

35. Asthma. American Acadamy of Allergy, Asthma \& Immunology. https://www.aaaai.org/conditions-and-treatments/asthma. Accessed March 27, 2019.

36. Asthma. National Heart Lung and Blood Institute. https://www.nhlbi.nih.gov/healthtopics/asthma. Accessed November 27, 2018.

37. Boden BP, Breit I, Beachler JA, Williams A, Mueller FO. Fatalities in high school and college football players. Am J Sports Med. 2013;41:1108-16.

38. Saydah S, Imperatore G, Cheng Y, Geiss LS, Albright A. Disparities in diabetes deaths among children and adolescents - United States, 2000-2014. MMWR Morb Mortal Wkly Rep. 2017;66:502-505. 
39. Scarneo SE, DiStefano LJ, Stearns RL, Register-Mihalik JK, Denegar CR, Casa DJ. Emergency action planning in secondary school athletics: A comprehensive evaluation of current adoption of best practice standards. J Athl Train. 2019;54(1):99-105.

40. Casa DJ, Hosokawa Y, Belval LN, Adams WM, Stearns RL. Preventing death from exertional heat stroke--the long road from evidence to policy. Kinesiol Rev. 2017;6(1):99-109.

41. Heat Stroke. Korey Stringer Institute. https://ksi.uconn.edu/emergencyconditions/heat-illnesses/exertional-heat-stroke/. Accessed March 27, 2019.

42. Sports Medicine. National Federation of State High School Associations. https://www.nfhs.org/resources/sports-medicine/. Accessed March 27, 2019.

43. Binkley HM, Beckett J, Casa DJ, Kleiner DM, Plummer PE. National athletic trainers' association position statement: Exertional heat illnessess. J Athl Train. 2002;37(3):329-343

44. Casa DJ, Csillan D. Preseason heat-acclimatization guidelines for secondary school athletics. J Athl Train. 2009;44(3):332-333.

45. Harmon KG, Asif IM, Klossner D, Drezner JA. Incidence of sudden cardiac death in National Collegiate Athletic Association Athletes. Circulation. 2011;123(15):15941600 .

46. Sudden Cardiac Death. Korey Stringer Institute. https://ksi.uconn.edu/emergencyconditions/cardiac-conditions/sudden-cardiac-death/. Accessed March 27, 2019.

47. Miller M, Weiler J, Baker R, Collins J, D’Alonzo G. National athletic trainers' association position statement: Management of asthma in athletes. $J$ Athl Train. 2005;40(3):224-245.

48. Census. West Virginia Fact Sheet. http://www.census.gov/. Accessed 10 June 2011.

49. Sarmiento K, Thomas KE, Daughtery J, et al. Emergency department visits for sportsand recreation-related traumatic brain injuries among children - United States, 20102016. MMWR Morb Mortal Wkly Rep. 2019;68(10):237-242.

50. Cervical Spine Injury. Korey Stringer Institute. https://ksi.uconn.edu/emergencyconditions/cervical-spine-injury/. Accessed March 27, 2019.

51. Swartz EE, Boden BP, Courson RW, et al. National athletic trainers' association position statement: Acute management of the cervical spine-injured athlete. $J$ Athl Train. 2009;44(3):306-331. 
52. Bailes JE, Petschaurer M,Guskiewicz KM, Marano G. Management of cervical spine injuries in athletes. $J$ Athl Train. 2007;42(1):126-134.

53. Waninger KN, Swartz EE. Cervical spine injury managemen in the helmeted athlete. Curr Sports Med Rep. 2011;10(1):45-49.

54. Schroeder GD, Vaccaro AR. Cervical spine injuries in the athlete. J Am Acad Orthop Surg. 2016;24:e122-e133.

55. Hew-Butler T, Rosner MH, Fowkes-Godek S, et al. Statement of the 3rd international exercise-associated hyponatremia consensus development conference, Carlsbad, California, 2015. Br J Sports Med. 2015;49(22):1432-1446.

56. Hyponatremia. Korey Stringer Institute. https://ksi.uconn.edu/emergencyconditions/exertional-sickling/. Accessed March 27, 2019.

57. Jones J. Sickle cell trait in sports. Hughston Health Alert. 2011;23(3):4-5.

58. Harmon KG, Drezner JA, Klossner D, Asif IM. Sickle cell trait associated with a RR of death of 37 times in national collegiate athletic association football athletes: A database with 2 million athletes-years as the denominator. Br J Sports Med. 2012;46:325-330.

59. Mitchell BL. Sickle cell trait and sudden death. Sports Medicine. 2018;4(19):1-6.

60. Quick Facts West Virginia. United States Census Bureau. https://www.census.gov/quickfacts/wv. Accessed April 1, 2019.

61. Kucera KL, Yau RK, Register-Mihalik J, et al. Traumatic brain and spinal cord fatalities among high school and college football players — United States, 2005-2014. MMWR Morb Mortal Wkly Rep. 2017;65:1465-1469.

62. Walsh KM, Cooper MA, Holle R, Rakov VA, Roeder WP, Ryan M. National athletic trainers' association position statement: Lightning safety for athletics and recreation. $J$ Athl Train. 2013;48(2):258-270.

63. Lightning. Korey Stringer Institute. https://ksi.uconn.edu/emergencyconditions/lightning/. Accessed March 27, 2019.

64. Coaching Education. Korey Stringer Institute. https://ksi.uconn.edu/prevention/coaching-education/. Accessed March 27, 2019. 


\section{APPENDICES}




\section{APPENDIX A}

\section{THE PROBLEM}

\section{Research Question}

In the secondary school setting, coaches are required to complete duties other than coaching of assigned sporting teams. ${ }^{1-5}$ In most cases and dependent on location, this can include medical coverage for athletes. Rural or low-income school districts may not have access to an athletic trainer or other healthcare professional to provide medical advice to athletes or coaches. ${ }^{1,3,5,7,8}$ Secondary school coaches at schools who do not have access to a full-time medical professional must be able to recognize, manage, and prevent injuries in their studentathletes. ${ }^{7,8}$ Thus, coaches at high schools are required to obtain a first aid and cardiopulmonary resuscitation (CPR) certification but do not need a degree or medical training. Despite this, secondary school coaches are responsible for the health, safety, and wellbeing of athletes without receiving formal education on possible pathologies. ${ }^{5,7,8}$ Therefore, it is important to understand the influence secondary school coaches have on the health of athletes and the effect injuries may have on the future.

Although able to recognize musculoskeletal injuries, secondary school coaches may not know about sudden death in athletics and the health concerns that arise from sudden death conditions in athletics. ${ }^{3}$ This can lead to concerns of being unable to recognize the signs and symptoms, to know the proper time to remove the athlete from participation, or when to activate an emergency action plan (EAP). Due to these concerns, educational efforts for coaches are accessible and required in select states to keep athletes safe as some states require coaches to receive educational training on injuries. ${ }^{8}$ 
In the state of West Virginia, all prospective coaches who are not currently teachers in a West Virginia Department of Education (WVDE) school must complete the West Virginia Secondary School Activities Commission (WVSSAC) Coaches Education course prior to working. ${ }^{11}$ The Sports First Aid Course is included in the 14-hour course that is required for any non-WVDE teacher coaches. The WVSSAC also requires completion of the National Federation of State High School Associations" "Concussion in Sport," "Heat Illness Prevention," and "Sudden Cardiac Arrest" online programs yearly for all coaches. ${ }^{11,14}$

The main concern surrounding risk in athletics is catastrophic injury or sudden death. In athletics, catastrophic sport injury or sudden death in sport is categorized by the National Athletic Trainers' Association (NATA) into ten conditions that are most common in athletics: asthma, catastrophic brain injuries, cervical spine injuries, diabetes, exertional heat stroke, exertional hyponatremia, exertional sickling, head-down contact in football, lightning, and sudden cardiac arrest. ${ }^{15-17,65}$ Catastrophic sport injuries can be classified as exertional or systematic indirect injuries that occur as a result of systemic failure during exertion. ${ }^{65,66}$ Athletic trainers have worked to address the topics of sudden death in sport through the use of research and best practice recommendations for other athletic trainers and populations working in sport. ${ }^{15-}$ $17,19,40$

Previous studies on this subject area have focused on coaches' certification in First Aid/CPR/AED. These studies have suggested that coaches are more confident in handling a medical emergency if certified in First Aid, CPR, or AED. ${ }^{1,2,21}$ However, recommendations that an athletic trainer should be present for all athletic events who is trained in management of sudden death conditions in athletics. ${ }^{2,15-17,21,23,24}$ Lastly, it is recommended that all school athletic 
program should develop a site-specific EAP, coordinate the EAP with local medical services and involved staff members, and rehearse annually. ${ }^{15,17,20,21,24-26}$

Nonetheless, if an athletic trainer or licensed health care professional is not present, coaches must assume responsibility when medical emergencies occur. Despite WVSSAC coaches completing a first aid and annual NFHS courses, it is unclear to determine if they are properly prepared for a medical emergency during practices or competition. This has led to the creation of the following research questions:

1. Does coaches' preparedness for sudden death conditions in sport vary depending on sport?

2. Do head coaches have more experience with recognizing medical emergencies than assistant coaches?

3. Does the WVSSAC Coaching Course adequately prepare coaches for sudden death in sport?

4. Are coaches who completed the WVSSAC Coaching Course better prepared than WVDE coaches regarding sudden death situations?

5. Does the coaches' cognizance level regarding medical emergencies vary with an athletic trainer present during practices and competitions?

6. Do coaches properly activate the EAP during medical emergencies?

\section{Experimental Hypotheses}

1. $75 \%$ of coaches will be First Aid/CPR/AED certified based on questionnaire responses.

2. $50 \%$ of coaches paid occupation will be as a teacher within a West Virginia Department of Education school based on questionnaire responses.

3. $75 \%$ of coaches will have taken an online course in recognizing concussions prior to coaching within the past 12 months based on questionnaire responses.

4. $50 \%$ of coaches will report a certified athletic trainer is the health care provider for the school based on questionnaire responses.

5. $50 \%$ of the coaches will report a non-athletic trainer is the health care provider for the school based on questionnaire responses. 
6. $75 \%$ of coaches will be exposed to and have dealt with an asthma situation, catastrophic brain injuries, cervical spine injuries, a diabetes situation, exertional heat stroke, headdown contact in football, and lightning.

7. $25 \%$ of coaches will be exposed to and have dealt with exertional hyponatremia and exertional sickling.

8. $50 \%$ of coaches will be exposed to and have dealt with sudden cardiac arrest.

9. $75 \%$ of coaches will report having an EAP for athletics based on questionnaire responses.

\section{Assumptions}

1. Participants will answer the questionnaire to the best of their ability and with honesty.

2. The questionnaire used is valid and reliable.

3. Participants will submit the survey completed in its entirety.

4. Participants will have knowledge of sudden death conditions in sport.

\section{Delimitations}

1. The participants of the study will consist of secondary school coaches in West Virginia only and cannot be generalized beyond the state.

2. The questionnaire will only evaluate catastrophic sport injuries.

Operational Definitions

1. Asthma - A chronic disease that causes the bronchial tubes to become inflamed to restrict airflow. ${ }^{15,35,36,47}$ Symptoms such as coughing, wheezing, and shortness of breath among others can occur as well as tightening muscles around the airways. ${ }^{15,35,47}$

2. Automated External Defibrillator - A device which delivers an electric shock to stop an arrhythmia to allow the heart to return to a normal sinus rhythm following sudden cardiac arrest. $^{67,68}$

3. Awareness - For this study, the self-reported knowledge, understanding, and perception of the sudden death conditions for West Virginia secondary school coaches.

4. Cardiopulmonary Resuscitation - An emergency lifesaving procedure performed when the heart stops beating which performed immediately can increase survival rates after cardiac arrest. ${ }^{68}$ 
5. Catastrophic Brain Injury - A traumatic brain injury such as a sports-related concussion which can occur in helmeted and non-helmeted sports. ${ }^{15,49,70-72,}$ Rare conditions include subdural and epidural hematomas and malignant cerebral edema.

6. Certified Athletic Trainer - A health care professional who provides care through five major practice domains including injury and illness prevention and wellness, examination, assessment, and diagnosis, immediate and emergency care, therapeutic intervention, and health care administration and professional responsibility. ${ }^{28}$

7. Cervical Spine Injury - The cervical spinal column undergoes structural distortion and can potentially or actually cause damage to the spinal cord. ${ }^{15,50,51,61,70,73,74}$

8. Diabetes Mellitus (Type I and Type II) - A chronic metabolic disorder that causes hyperglycemia due to an insulin deficiency or resistance to the action of insulin causing the inability to self-regulate blood glucose levels. ${ }^{15,38,75,76}$

9. Emergency Action Plan - A written document which is developed and coordinated with school medical staff, school administrators, school public safety officials, local emergency medical staff, and onsite first responders that includes instructions in the event of an emergency during an athletic session. ${ }^{15,20,26}$ Should be specific to each athletic venue and be practiced at least annually with all involved parties.

10. Exertional Heat Stroke - Core body temperature greater than $104 \mathrm{~F}$ to $105 \mathrm{~F}$ with an associated central nervous system dysfunction. ${ }^{15,40,44,77}$

11. Exertional Hyponatremia - Serum sodium concentration falls less than $130 \mathrm{mEq} / \mathrm{L}$ with risk of encephalopathy. ${ }^{15,55,56,777,78}$ Signs and symptoms include lightheadedness, dizziness, nausea, puffiness, body weight gain from baseline, vomiting, headache, altered mental status, seizure, or coma. ${ }^{55,56}$

12. Exertional Sickling - Genetic risk factor from sickle cell trait where symptoms can be brought upon with intense, sustained activity that continues to increase intensity. ${ }^{15,79,80}$ Signs and symptoms include muscle cramping, pain, swelling, weakness, inability to catch one's breath, fatigue, and collapse. ${ }^{15}$

13. Head-Down Contact in Football - Causes a cervical spine fracture or dislocation above C4 due to axial loading following the head-down contact in football players. ${ }^{15,51,73}$

14. Lightning - A natural phenomenon that is one of the most dangerous natural hazards. ${ }^{15,62,63}$ Can occur cloud to cloud or cloud to ground from negatively charged ionized gas that is built up in clouds which seeks positively charged regions. ${ }^{15,62}$ 
15. Limited Football Trainer - A licensed health care provider that may be a physician, registered nurse, licensed practical nurse, chiropractor, physical therapist, occupational therapist, physician's assistant, paramedic, or emergency medical technician who will provide health care services to all West Virginia high school football events in the event the school district cannot hire an athletic trainer. ${ }^{28}$

16. Preparedness - For this study, the self-reported readiness to provide care by West Virginia secondary school coaches for sudden death conditions if care is necessary.

17. Sports First Aid Course - A section within the 14-hour WVSSAC Coaches Course that is required for prospective, non-WVDE coaches prior to coaching duties along with a completion grade of at least $80 \% .^{11}$

18. Sudden Cardiac Arrest - The leading cause of death in exercising young athletes which is caused by a structural cardiac abnormality. ${ }^{15,46,67}$ Abnormalities may include hypertrophic cardiomyopathy, coronary artery anomalies, commotio cordis, and others. ${ }^{15}$

Limitations

1. Only using WVSSAC secondary school coaches.

2. The questionnaire used is not a validated questionnaire.

3. The participants may have a biased opinion of sudden death conditions in athletics.

4. The questions on the questionnaire may be misunderstood.

5. The participants will not be in a controlled setting and become distracted during completion.

6. The participants may not remember situations involving sudden death in athletics and may answer incorrectly.

Significance of the Study

Sudden death in athletics is a topic which has been heavily researched to determine best practice recommendations to prevent death from occurring. Despite the extensive knowledge that athletic trainers possess on recognizing sudden death signs and symptoms, the responsibility may often fall to coaches. This becomes a cause for concern as coaches may not have the education or training to understand the repercussions from not identifying the signs and symptoms sooner. 
It is imperative to research if coaches are prepared for a medical emergency if there is not a health care professional present. The importance of this research is to determine the level of WVSSAC coaches' preparedness on sudden death in athletics in the state of West Virginia. It will also be used to determine whether the WVSSAC Coaching Course is sufficient in educating coaches on first aid and medical emergencies. In the event of a lack of medical personnel, coaches must be responsible to determine if a student athlete must be removed from participation. Thus, this study can recommend the importance of a designated health care professional and determine if all coaches should be required to complete further education on sudden death in sport.

Currently other healthcare professionals are hired for only high school football practices and games in the state of West Virginia. These individuals may not be properly trained to reduce sudden death risk, advocate for athlete health, and improve future quality of life for athletes. The goal of this study is to share information with the WVSSAC. This may lead to the recommendation by the WVSSAC for school administrators to require an athletic trainer in all schools. With this recommendation, safer athletic sessions in secondary schools will be created. Since this is the first study to be completed studying medical emergency preparedness on West Virginia coaches, it will allow future research to occur and for the WVSSAC to be aware of this need. The findings from this study will be shared with classmates, colleagues, and distributed to universities through the use of pamphlets and e-mails. 


\section{APPENDIX B}

\section{LITERATURE REVIEW}

Introduction

A certified athletic trainer is recommended during all high school sports' practices and competitions and endorsed by multiple sports medicine governing organizations. $1,2,15,16,23,24$ However, in high schools and rural areas, the school board may not have the ability to hire an athletic trainer for athletics. ${ }^{1,3,4}$ This leads to secondary school coaches' role in sport extended further than teaching and leading athletes in practice and competition. If a school is unable to employ an athletic trainer for secondary school athletics, medical care as well as application of the emergency action plan (EAP) becomes the responsibility of the coaches and athletic director. ${ }^{9}$ Duties may encompass the health and safety of student-athletes by recognizing and providing emergency care for sudden death conditions. ${ }^{1,2,10}$ This may be attributed to a lack of health care professionals present.

In the state of West Virginia, coaches have varying requirements related to medical emergency preparation which must be completed prior to working. Individuals who are not teachers within a West Virginia Department of Education (WVDE) school must complete the West Virginia Secondary School Activities Commission (WVSSAC) Coaches Education Course. This on-site 14-hour course provides a sports first aid section in addition to other coaching responsibilities. ${ }^{11}$ Prospective coaches must also score at least $80 \%$ for three online tests (Sport Science, Sport First Aid, and West Virginia Component for rules and regulations) at the completion of the course. ${ }^{11}$ Certified teachers through the WVDE do not have to complete the Coaches Education course. The WVSSAC Coaching Course can also be taken for college credits through West Virginia University with three from "Coaches Education" and two from "Sports 
First Aid." ${ }^{11}$ However, the teachers and non-teacher coaches must complete the National Federation of State High School Association (NFHS) "Concussion in Sport," Heat Illness Prevention," and "Sudden Cardiac Arrest" annually. ${ }^{11,13}$

The following headers are included in this literature review: secondary school coaches' preparedness for sudden death conditions, coaching requirements in West Virginia secondary schools, emergency action plan, athletic trainer's role in emergency preparedness, and sudden death in athletics.

Secondary School Coaches’ Preparedness for Sudden Death Conditions

The National Athletic Trainer's Association (NATA) urges that all coaches should be trained in first aid, cardiopulmonary resuscitation (CPR), and automated external defibrillator (AED) use. ${ }^{1,2,15,16,24}$ The ability to gain immediate access to an AED has been cited to maximize sudden cardiac arrest survival rates. ${ }^{68,81,82}$ It is imperative that coaches are versed and certified in First Aid/CPR/AED in order to begin lifesaving measures until medical professionals arrive. Seven-hundred and forty high school coaches were surveyed on knowledge of first aid, CPR, AED use, and confidence in emergency situations. ${ }^{2}$ Sixty-eight percent of coaches were certified in CPR/AED use remained more confident in the ability to answer than coaches who were not. ${ }^{2}$ There was also a statistically significant difference between certified and non-certified coaches in CPR/AED regarding knowledge of CPR/AED use. ${ }^{2}$

Oregon secondary school athletic directors were surveyed on sports-related emergency preparedness and if the best practice recommendations were implemented. These best practice recommendations include venue-specific emergency action plans (EAP), access to early defibrillation, and first responders, which was specifically coaches, trained in CPR/AED. ${ }^{21}$ Of the 108 participants, $11 \%$ of schools implemented all three best practice recommendations. ${ }^{21}$ 
Schools with an athletic trainer present reported using venue-specific EAPs. Fifty-two percent at those sites used the site-specific EAP as compared to schools without an athletic trainer. ${ }^{21}$ Also, those with an athletic trainer resulted in $69 \%$ having access to an AED compared to $44 \%$ without an athletic trainer. ${ }^{21}$ However, despite having an athletic trainer present, $33 \%$ of schools required coaches' CPR/AED certification compared to $28 \%{ }^{21}$ Adams et al ${ }^{83}$ studied secondary school football coaches' perceived knowledge of exertional stroke. A highlighted theme included selfconfidence of the coaches regarding basic emergency care training and management of an emergency situation yet limited knowledge of the causes or symptoms of exertional heat illness. ${ }^{83}$ However, coaches reported understanding the importance of an athletic trainer during emergency situations. ${ }^{83}$

Coaches are also recommended to plan practices to protect athletes. Coaches could change practice to different times of day so that the temperature is lower in order to reduce the risk of heat illness. ${ }^{6,17}$ This can allow athletes to become acclimatized to the weather as well as possible equipment. ${ }^{6,15,17}$ When storms are in the vicinity, coaches who are participating in practices outdoors can coordinate to move indoors where the threat of lightning injuries are diminished. ${ }^{62-64}$ Also, furthering the education of coaches with courses and information can reduce the risk of sudden death conditions and sport-related injuries. Suggestions include proper equipment fitting, injury prevention techniques and interventions, hydration preparedness, nutrition, and the CDC's Heads Up online course and videos. ${ }^{64,84}$

Coaching Requirements in West Virginia Secondary Schools

In the state of West Virginia, 36,903 high school student-athletes participated in WVSSAC sanctioned sports in 2017-2018. ${ }^{85}$ The WVSSAC requires that all coaches must initially become First Aid/CPR/AED certified but lack the requirement to maintain the 
certification. ${ }^{1,11}$ Of the 62 respondents, $33 \%$ of West Virginia high schools always require the coaching staff to maintain CPR/AED certification, while $31 \%$ never required coaches to remain certified. ${ }^{1}$ As coaches may assume the role as medical provider in the absence of an athletic trainer or other licensed health care professional, it is imperative that coaches maintain the $\mathrm{CPR} / \mathrm{AED}$ certification in order to remain confident and prepared for a situation that requires use of CPR or an AED. Also, coaches must complete "Initial and Renewal of Coaching, Limited Football Trainer, and Athletic Trainer Authorizations (Form 39)" and be approved by the WVDE and the county superintendent in which the coach is employed. ${ }^{86}$ Coaches are also required to complete the NFHS Concussion in Sport," Heat Illness Prevention," and "Sudden Cardiac Arrest" online every 12 months. ${ }^{11,42,64}$

West Virginia public schools require an athletic trainer be present for all senior high school football practices, scrimmages, and games. ${ }^{28}$ The athletic trainer must be certified through the Board of Certification, registered as an athletic trainer within the West Virginia Board of Physical Therapy, and recommended by the superintendent of the county in which he or she would work. ${ }^{28}$ If the school is unable to hire an athletic trainer, the county may obtain a licensed health care provider with limited football trainer authorization who can include physician, registered nurse, licensed practical nurse, chiropractor, physical therapist, occupational therapist, physician's assistant, paramedic, or emergency medical technician. ${ }^{28}$ Athletic trainers or limited football trainers are required to complete "Initial and Renewal of Coaching, Limited Football Trainer, and Athletic Trainer Authorizations (Form 39)" provided by the WVDE annually to obtain approval from the WVDE as well as the hiring county superintendent. ${ }^{28,86}$ An additional requirement is the attendance of a workshop or clinic by the WVSSAC. ${ }^{28}$ However, an athletic 
trainer or limited football trainer is only required for football and coverage of other sports is not mandatory.

Emergency Action Plan

In the event of a medical emergency, the proper personnel can be contacted in order to reduce time to maximize survival. The NATA recommends that any organization, school, or sponsor of athletic events should create a written emergency action plan (EAP) to be activated after recognition of a medical emergency. ${ }^{1,2,10,15,16,20,21,26}$ The EAP is a written document that is developed and coordinated with school medical staff, school administrators, school public safety officials, local emergency medical staff, and onsite first responders that includes instructions in the event of an emergency during an athletic session. ${ }^{15,20,26}$ This document should be specific for athletics based on the management of serious sport-related injuries. ${ }^{20,26,31}$ There should be sitespecific EAPs and visible at all locations with possible maps or directions for emergency medical services. ${ }^{1,2,10,15,16,20,21}$ Best practice recommendations suggest the EAP to be coordinated with onsite first responders who provide medical coverage during games and practices, school medical staff, school administrators, and local EMS responders and should be practiced yearly with all those who may be involved..$^{10,15,16,20,26,64}$ The document should include on-site emergency equipment such as an AED, identify personnel and responsibilities within the EAP, and specify post-emergency documentation. ${ }^{20,21,31}$ Distribution of the EAP should be for all athletic staff members. ${ }^{20,21,26,64}$

Twenty-four state athletic associations (47\%) within the United States of America recommend developing an EAP. ${ }^{20}$ Valovich McLeod et $\mathrm{al}^{32}$ reported $95 \%$ of Arizona secondary school athletic directors had a written EAP and 93\% had an AED available at the school. Specifically, the study also reported the athletic directors were aware of the Arizona 
interscholastic concussion policy, had a school-specific concussion policy (98\%), and familiar with the state heat-illness policy (99\%). ${ }^{32}$ Lastly, if the secondary school had access to an athletic trainer, the school was more likely to have an EAP available, a venue-specific EAP, physician approval of the EAP, AEDs available, heat illness policies, and cold-water immersion tubs..$^{32} \mathrm{~A}$ study ${ }^{39}$ evaluated secondary school EAPs to determine if the "National Athletic Trainers' Association Position Statement: Emergency Planning in Athletics"26 best practice recommendations were met. Eighty-nine percent of athletic trainers across the United States reported an EAP however 9.9\% implemented all of the components. ${ }^{39}$ Also, if athletic trainers were hired full time, more components of the EAP were present compared to part time employment. ${ }^{39}$

EAPs are necessary in athletics due to multiple reasons. As emergencies can occur quickly and unexpectedly, EAPs are important to allow an organized response to a medical emergency. ${ }^{26}$ Andersen et $\mathrm{al}^{26}$ reported that emergency plans are applicable to government agencies that include law enforcement, fire and rescue, and federal emergency management teams. It may minimize the risks associated with the emergency due to the EAP ensuring organization during chaos. ${ }^{26}$ The National Collegiate Athletic Association (NCAA) and NFHS recommends the development of an EAP for all athletic programs. ${ }^{15,16,26}$ Andersen et al ${ }^{26}$ also recommends an EAP due to the legal need surrounding an emergency. Gathers v Loyola Marymount University settled in state court and stated care was delayed as the defendants were negligent and careless to not provide an appropriate emergency response..$^{26,87}$

The Korey Stringer Institute ${ }^{27}$ listed an athletics EAP is available for West Virginia high schools or organizations which sponsor athletics. Contradicting this information, Adams et al ${ }^{20}$ reported West Virginia does not require an EAP for athletics. Despite these conflicting results, 
the WVSSAC requires an EAP to be completed and uploaded to the organization's website for each sport at every school. ${ }^{12,13}$ Titled "Emergency Action Plan Worksheet - Student Response Team," this document ensures coaches and athletes are prepared to provide care and alert emergency medical services through the use of a 911 Team, CPR/AED Team, AED Team, and Heat Stroke Team. ${ }^{13}$ The form and directions are available on the WVSSAC website (Figure B1). Figure B1. WVSSAC Emergency Action Plan Worksheet - Student Response Team ${ }^{13}$

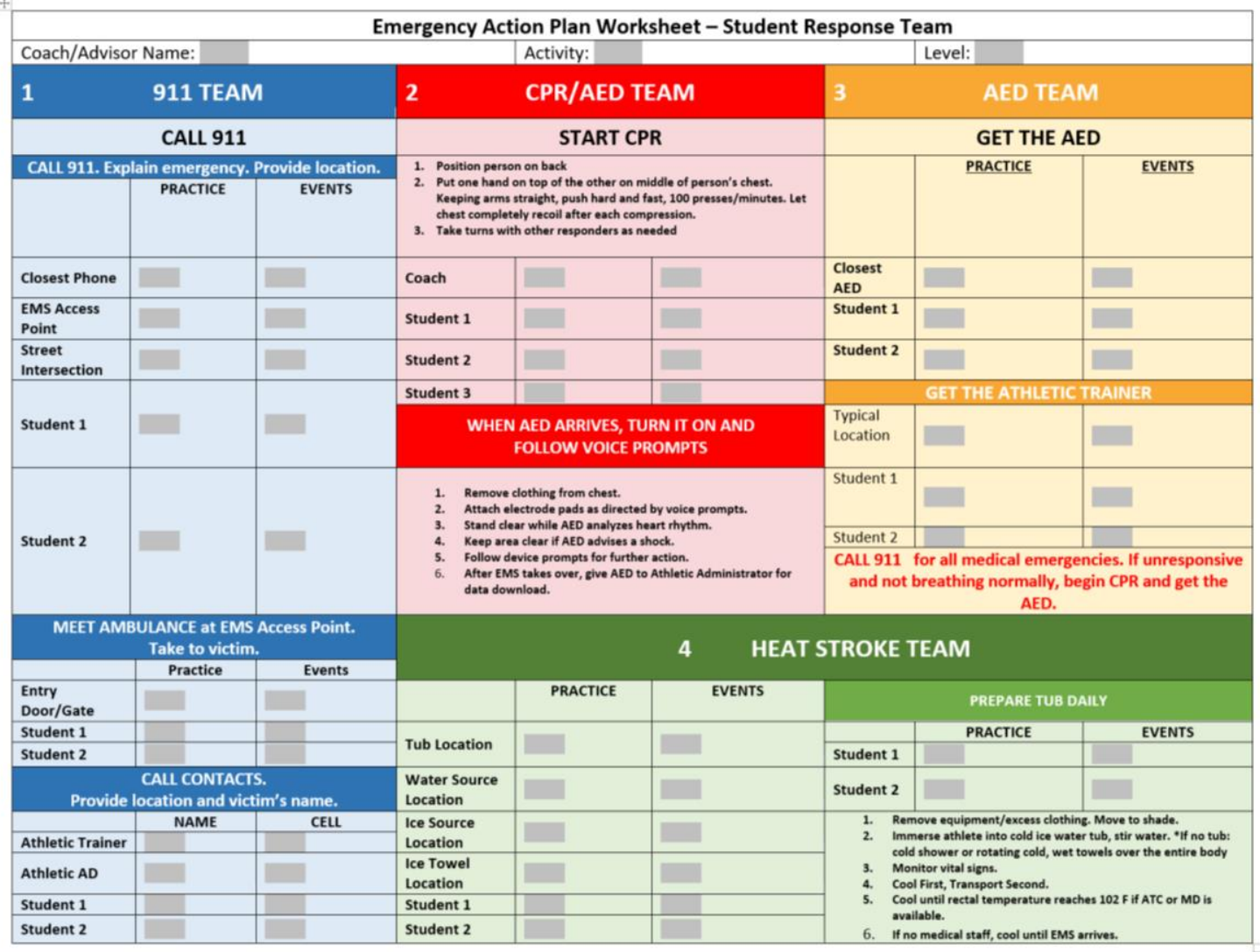

Athletic Trainer's Role in Emergency Preparedness

The athletic trainer is educated in emergency medicine and works as a first responder. ${ }^{1,18}$ Athletic trainers are prepared to handle medical emergencies and taught the best practice recommendations for conditions which include sudden death in athletics. ${ }^{15,16,18}$ To maintain the ATC certification, the athletic trainer must provide proof of CPR/AED recertification to the Board of Certification as well as completion of continuing education units. ${ }^{18}$ The five domains 
athletic trainers are educated in include injury and illness prevention and wellness promotion, examination, assessment, and diagnosis, immediate and emergency care, therapeutic intervention, and health care administration and professional responsibility. ${ }^{18}$ Pryor et al ${ }^{10}$ reported athletic trainers were present in $70 \%$ of public secondary schools however only $37 \%$ of schools reported a full-time athletic trainer. In the state of West Virginia, 85\% of schools reported athletic trainer services with $46 \%$ with a full time athletic trainer. ${ }^{10}$ Additionally, it was reported athletic trainers were present for practice coverage daily for $67 \%$ of schools. ${ }^{10}$ In Arizona, it was reported access to an athletic trainer increased the likelihood the secondary school would have venue specific and physician approved EAPs, access to AEDs and heat illness policies such as cold-water immersion tubs. ${ }^{32}$

As stated in the third domain of immediate and emergency care, athletic trainers are educated in preventing, recognizing, and treating sudden death conditions unlike coaches. ${ }^{1,18}$ These health care professionals can provide proper medical care and appropriate referral which can include activation of the EAP and emergency medical services. The athletic trainer should be included in the EAP as the health care professional who provides medical coverage. ${ }^{15,20,26}$ In addition, the athletic trainer is instrumental in activating the EAP and ultimately returning the athlete to play following rehabilitation and treatment for the condition. ${ }^{15}$ Lastly, it is recommended that athletic trainers be present for all practices and games for contact or collision sports such as baseball, basketball, diving, football, ice hockey, lacrosse, pole vaulting, soccer, softball, and wrestling. ${ }^{15,26}$

Sudden Death in Athletics

The NATA released a position statement in 2012 highlighting 10 sudden death conditions which are commonly observed in athletics and physical activity. ${ }^{15}$ The conditions covered in this 
statement include asthma, catastrophic brain injuries, cervical spine injuries, diabetes mellitus, exertional heat stroke, exertional hyponatremia, exertional sickling, head-down contact in football, lightning, and sudden cardiac arrest. ${ }^{15}$ Additionally, the NATA completed a consensus statement comprised of an inter-task force on prevention of sudden death in secondary school athletics. ${ }^{16}$ The consensus statement cites the leading sudden death causes in high school athletes as head and neck injuries, exertional heat stroke, sudden cardiac arrest, and exertional sickling. ${ }^{16}$ Asthma

Asthma is characterized as a chronic inflammatory disease that causes the bronchial tubes to become inflamed, which affects an estimated 25 million people in the United States. ${ }^{16,35,36,47}$ From 1990-2010, seven high school and college football players died from asthma complications. ${ }^{37}$ This disorder leads to airway obstruction due to the inflammation and bronchial hyperresponsiveness. ${ }^{36}$ Signs and symptoms include wheezing, shortness of breath, chest tightness, coughing, and use of accessory muscles for breathing. ${ }^{15,47,88}$ The previously listed symptoms can occur from changes in environment, during or after exercise, allergens, smoke, pollutants, exposure to cold, or respiratory infections. ${ }^{16,35,36,47}$ Asthma symptoms can be prevented during sport with a proper warmup prior to sport activity. It is also important for proper education prior to sport participation to recognize and treat athletes experiencing asthma symptoms. ${ }^{15,47}$ Recognition of asthma symptoms are the previous symptoms and also includes confusion, sweating, drowsiness, forced expiratory volume of the first second $\left(\mathrm{FEV}_{1}\right)$ less than $40 \%$, and low oxygen saturation..$^{9,15,36,47}$ Treatment for athletes experiencing asthma symptoms involves the use of asthma medications such as short-acting $\beta_{2}$-agonist inhaler and inhaled corticosteroids which are known as quick-relief or rescue inhalers. ${ }^{15,35,36,47}$ Athletes may also use 
a long term inhaled corticosteroid to be administered daily to control symptoms but not to be used for acute symptoms. ${ }^{35,47}$

If the athlete begins to experience respiratory distress such as cyanosis, hypotension, bradycardia or tachycardia, mental status change, or loss of consciousness, the EAP should be activated and 911 should be called. ${ }^{15,36,47,88}$ Vital signs should be monitored in case of the need for CPR and the athlete should try to use the inhaler. ${ }^{15,36}$ If the athlete experiences asthma symptoms without any respiratory distress, the athlete should use the rescue inhaler, monitor for improvement, and utilize the peak flow meter to measure peak expiratory flow (PEF) to determine proper lung function to determine the next steps. ${ }^{15,47}$ Return to play following asthmatic symptoms requires the athlete to be asymptomatic, lung function to be measured with a peak flow meter to have PEF be within limits of the baseline measurement, and monitoring of symptom triggers for practices and competitions..$^{15,47}$

Catastrophic Brain Injuries

Catastrophic or traumatic brain injuries include concussion, skull fractures, intercranial hemorrhages, diffuse cerebral edema (second-impact syndrome), subdural and epidural hematoma, and malignant cerebral edema. ${ }^{15}$ In 2014, there were an estimated 2.87 million traumatic brain injury emergency department visits in the United States, approximately 837,000 of those were children. ${ }^{89}$ In that same year, 56,800 total deaths and 2,529 children deaths occurred from traumatic brain injuries. ${ }^{89}$ Boden et $\mathrm{al}^{37}$ reported 62 high school and college football athlete deaths stemming from brain injuries from 1990-2010. It was estimated that 329,290 adolescents aged 19 or younger required treatment for a sport or recreation-related concussion or traumatic brain injury in $2012 .{ }^{89,90}$ Also, $45 \%$ of all sport and recreation-related traumatic brain injuries that required referral to an emergency department were sustained in 
contact sports. ${ }^{49}$ Coronado et al ${ }^{90}$ reported an increase of sport related traumatic brain injuries in males and females from age 0-19. Males also registered nearly twice the traumatic brain injuries as female counterparts in all age groups. ${ }^{90}$ Male sports with the highest rates of traumatic brain injuries include bicycling, football and basketball while female sports with greatest rates include bicycling, playground activities, and horseback riding. ${ }^{49,90}$ Contact sports recorded the greatest number of emergency referrals in males $(99,784)$ and females $(27,180)$ from 2010-2016 with football emergency department visits $(52,088)$ the highest rate for all male sports. ${ }^{90}$

The NATA's position statement recommends that prevention of catastrophic brain injuries begins with educating athletes and coaches on recognizing signs and symptoms, the importance of reporting symptoms of concussion, and not participating while symptomatic. ${ }^{15,70,71}$ In addition, limiting contact with players as well as possible rule changes that reduces collisions can prevent traumatic brain injuries in sports. ${ }^{49}$ Recognition of a specific catastrophic brain injury and concussion utilizes pre-season and post-injury assessments. ${ }^{15}$ It should be used in conjunction with a concussion assessment battery that evaluates cognition, balance, and selfreported symptoms. ${ }^{15,70,71}$ Symptoms of a concussion can include cognitive (difficulty remembering or concentrating, feeling slowed down), physical (headache, dizziness, nausea and vomiting, sensitivity to light or noise), emotional (irritability, increased emotions, nervousness, sadness), or sleep disturbances (sleeping more or less, difficulty falling asleep) ${ }^{90}$ Treatment is dependent on sign and symptom severity whether to refer an athlete to an emergency department or to be sent home with instructions of care. ${ }^{15,70,71}$ Observable red flags which require immediate referral to an emergency department due to other serious traumatic brain injuries include decreased consciousness, loss or fluctuating consciousness, numbness in arms or legs, repeated vomiting, seizures, slurred speech or inability to speak, or increased confusion or irritability. ${ }^{70}$ 
These symptoms can be signs and symptoms of other catastrophic brain injuries other than a concussion. If athlete's cognitive function begins to decline through the time of care, the athlete should be referred immediately to a physician or emergency department. ${ }^{15,70,71}$ Athletes returning to play following a catastrophic brain injury should follow a gradual return to play progression once asymptomatic and before returning to competition ${ }^{15,70,71}$ In the state of West Virginia, if a concussion is suspected, athletes are not permitted to return to sport or activity on the same day. ${ }^{12}$ Athletes must be cleared by an appropriate health care professional such as an doctor of medicine, certified athletic trainer, physician's assistant, or advanced practice registered nurse prior to completion of a 5-step gradual return to play protocol. ${ }^{12}$ Concussion questions such as previous history and dates of concussions or head injuries are also asked on the preparticipation examination. $^{12}$

Cervical Spine Injuries

Cervical spine injuries occur after a structural distortion of the cervical spinal column that may potentially or actually damage the spinal cord. ${ }^{15,50,51,53}$ Annually, there are an estimated 12,000 cervical spine injuries of which $8 \%$ result from sports. ${ }^{50}$ Boden et $\mathrm{al}^{37}$ reported four deaths of high school football players from 1990-2010 from cervical spine injuries. Sudden death risk is augmented when the injury is above $\mathrm{C} 5$ that affects circulation or breathing control from the brain. ${ }^{15,50,51}$ Yet the incidence of quadriplegia is a risk factor as it occurred in 1.58 of 100,000 athletes from the year $1971-1975 .^{52,53}$ Often, axial loading of the cervical spine is the mechanism of injury when the vertebrae are compressed..$^{51,52,73,91,92}$ In an axial loaded position, musculature cannot assist in absorbing forces along with intervertebral discs. ${ }^{51,52,92}$ The mechanism of injury is often exhibited in American football when tackling. ${ }^{37,50,52,61,92}$ Common injuries are cervical fractures, intervertebral disc herniation, cervical spine dislocations, and quadriplegia. ${ }^{50,52,92}$ 
Recognition of suspected cervical spine injuries should include midline spine pain with or without palpation, bilateral neurological complaints, loss or altered level of consciousness, and obvious spinal column deformity. ${ }^{50-52}$ It is recommended that with any numbness, weakness, paralysis, or neck pain should be suspected of a cervical spine fracture. ${ }^{50-52}$ Treatment of cervical spine injuries involves immediate activation of the EAP and transportation to a medical facility with as little motion as possible. ${ }^{15,51,54}$ The athlete should be transported and immobilized on a long spine board. ${ }^{15,51}$ To achieve this, the athlete's cervical spine should be manually stabilized and held in a neutral position until external devices such as foam head blocks or cervical collar can be used to stabilize the cervical spine. ${ }^{15,51,54}$ The airway should become easily accessible by removing facemasks or other equipment with little to no movement and responders should be prepared to administer rescue breaths if need arises. ${ }^{15,51,53,54}$ In the event of a protective facemask on a helmet, the facemask should be immediately removed to expose the airway. ${ }^{50-54}$ Additionally, if rescue breathing is necessary, the jaw-thrust maneuver should be performed rather than the head-tilt technique to reduce movement of the spine and head. ${ }^{51,52}$ Equipment such as helmets or shoulder pads may complicate transportation, but those part of the EAP should be prepared to access vital life functions and maintenance of a neutral head and neck. ${ }^{15,51}$ It is recommended to leave equipment on until removed at the emergency department or controlled facility. ${ }^{53,54}$ However, the removal of equipment must be "all or none" meaning both shoulder pads and helmet (American football) must be removed simultaneously to continue alignment of the spine..$^{53}$

\section{Diabetes}


Diabetes (Type I and Type II) is a chronic metabolic disorder which causes hyperglycemia or hypoglycemia. ${ }^{15,34,75}$ In $2015,30.3$ million cases of diabetes were reported in the United States. ${ }^{33,34}$ It is estimated there are 200,000 cases of diabetes in patients under the age of $20 .{ }^{33,38}$ Additionally, from 2012-2014, there were 228 diabetes-related deaths in those under the age of $19 .{ }^{38}$ This condition is caused by an absolute insulin deficiency (Type I) or a resistance to insulin (Type II) which will affect the athlete's ability to regulate blood glucose levels within normal limits of $70-110 \mathrm{mg} / \mathrm{fL}^{15,33,75}$ Hyperglycemia is classified as low ( $\left.<70 \mathrm{mg} / \mathrm{dL}\right)$ blood glucose which can occur rapidly and can lead to an acute risk of death. ${ }^{75,76}$ Hypoglycemia is high (>180 mg/dL) blood glucose levels that may lead to long term health consequences issues however it does not carry a risk of sudden death immediately. ${ }^{75,76}$

Prevention of hyperglycemia can be achieved through frequent blood glucose monitoring, consuming carbohydrate supplements, and adjusting insulin as necessary. ${ }^{15,75} \mathrm{It}$ is recommended for athletes to consume meals and snacks on a regular schedule. ${ }^{76}$ Also, athletes should create and follow a diabetes care plan which includes blood glucose monitoring guidelines, insulin therapy guidelines, medication list, hypo-/hyperglycemia recognition and treatment guidelines, and emergency contact information. ${ }^{75,76}$ Recognition of symptoms of hyperglycemia include dizziness, hunger, nervousness, trembling, palpitations, sweating, or loss of consciousness and even death. ${ }^{15,75}$ Athletes experiencing hyperglycemia should be treated with 10-15 grams of carbohydrates following testing blood glucose levels. ${ }^{75}$ If the athlete is unable to follow directions, swallow, or becomes unconscious, the EAP should be activated and a trained health care professional should administer glucagon. ${ }^{15,75}$ Athletes along with parents, physicians, and athletic trainers should determine a safe blood glucose range in which the athlete can participate in sport and include in the diabetes care plan. ${ }^{15,75}$ 


\section{Exertional Heat Stroke}

Exertional heat stroke is a condition which occurs when the core body temperature exceeds $104^{\circ}$ to $105^{\circ} \mathrm{F}$ as well as with a disordered central nervous system..$^{9,15,17,43,44}$ Due to hyperthermia, organ system failure and a systemic inflammatory response may occur which central nervous system neurologic changes are cited as the first signs of exertional heat stroke. ${ }^{43}$ Excessive endogenous heat production or inhibited heat loss will affect the temperature regulation system causing an overwhelmed response of thermoregulatory system failure. ${ }^{15,43}$ This metabolic heat production from working musculatures and environmental heat load causes excessive heat production, decreased sweating response, and inability to evaporate sweat away from the body. ${ }^{17}$ Wet bulb globe temperature is recommended to determine if hot and humid conditions are safe for practices or games. ${ }^{17,93}$ While exertional heat stroke risks are common with hot and humid conditions, this sudden death condition may occur in "normal" environmental conditions as well. ${ }^{17,93}$ Grundstein et al $^{93}$ reported fatal exertional heat stroke in northern regions of the United States occurred at lower wet bulb globe temperatures. Fall athletes have been cited to have higher rates of exertional stroke than other season sports. ${ }^{43,93}$ Boden et $\mathrm{al}^{37}$ reported 38 heat-related deaths in high school and college football players from year 19902010. Additionally, it was reported the average temperature was $79.8^{\circ}-89.6^{\circ} \mathrm{F}$ for the football fatalities yet the core body temperature average was $107.8^{\circ} \cdot{ }^{37}$ Also, Yeargin et al ${ }^{95}$ reported exertional heat illnesses occurred in nearly all NCAA sports, of which 75\% were with football, with the majority of cases happening in preseason practices.

Prevention includes achieving proper exercise intensity for fitness levels and increased rest during dangerous environmental conditions. ${ }^{15,43}$ Also, it is recommended to modify practices and games based off of environmental wet bulb globe temperature to reduce heat stroke risk 
during participation. ${ }^{24,41,93}$ Hydration and cooling stations should be accessible for athletes at all times and is it recommended to perform weigh-ins and weight-outs to determine sweat loss over the course of practice. ${ }^{15,24,41}$ Symptoms of exertional heat stroke include disorientation, confusion, dizziness, diarrhea, irritability, delirium, collapse, vomiting, loss of consciousness, or coma. $^{15,43}$ The literature recommends education of heat stroke for coaches and athletes to understand symptoms to quickly identify a suspected case. ${ }^{15,24,43}$ Also, pre-disposing factors such as history of heat illness, illness, increased body mass index, poor physical condition, medication, and equipment usage can increase the risk of exertional heat stroke during practice or games. ${ }^{9,24,43}$ Temperature should be taken accurately with a rectal thermometer or ingestible thermistors only to ensure correct core body temperature. ${ }^{15,24,43}$ Cold water immersion in a tub should commence immediately to lower the core body temperature to less than $102^{\circ} \mathrm{F}$ within 30 minutes of collapse or symptoms then transported to an emergency department following activation of the EAP. ${ }^{15,17,41,43}$

Prevention of exertional heat stroke also includes a gradual acclimatization period over fourteen days to progressively challenge the athlete in the heat. ${ }^{15,17,24,41,43,44}$ The NATA recommends a preseason heat-acclimatization for secondary school athletics listed in Figure B2. ${ }^{17,44}$ Recommendations include days one through five to consist of formal practice once per day for no longer than three hours. ${ }^{17,44}$ Moreover, for helmeted sports, days one and two should be helmets only with the addition of shoulder pads on days three and five. ${ }^{44}$ Lastly, day six allows full protective equipment and full contact practice to occur. ${ }^{44}$ The heat-acclimatization period should progressively increase intensity and duration of activity. ${ }^{17}$ 
Figure B2. NCAA Heat-Acclimatization Guidelines. ${ }^{17}$

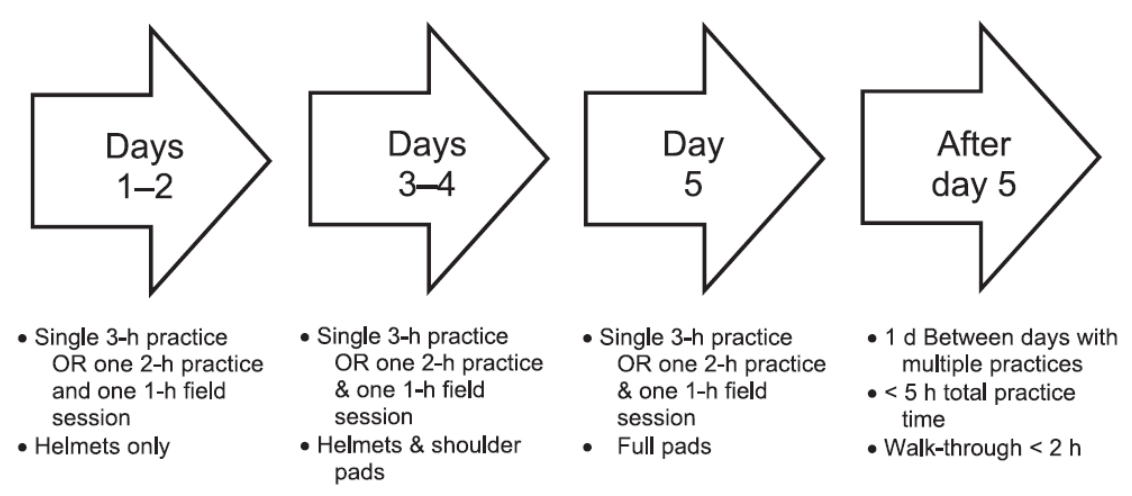

Exertional Hyponatremia

Exertional hyponatremia is a serum, plasma, or blood sodium concentration less than $135 \mathrm{mmol} / \mathrm{L}$ during or immediately completing exercise. ${ }^{15,43,55,56}$ Exertional hyponatremia can occur from overhydration or ingestion of hypotonic fluid in excess of sweat and urine output. ${ }^{43,55,56}$ Common activities which exertional hyponatremia exhibited and with known deaths include endurance competitions such as marathon, triathlons, and ultramarathons, hiking, military exercises, police training, and football as it has been reported in up to $30 \%$ of ultraendurance participants. ${ }^{55,56}$ Risk factors associated with this sudden death condition include continued excessive fluid intake which is more than excretion of fluids through sweat and respiratory and renal water excretion. ${ }^{15,55,56}$ Other risk factors include exercise longer than four hours, females, low body weight, abundant availability of fluids at the event, nonsteroidal antiinflammatory drugs, or extreme temperatures. ${ }^{56}$

Prevention includes proper individualized hydration protocol with the use of sweat rate, sport, environmental conditions, and exercise intensity and duration. ${ }^{15,43,55}$ Prevention can also include weigh-ins and weigh-outs prior and following exercise to monitor fluid consumption and body weight changes ${ }^{55}$ Also, instruction to athletes to drink to thirst can prevent exertional hyponatremia (Figure B3). ${ }^{55}$ Severe signs and symptoms include overdrinking, dizziness, 
disorientation, headache, altered mental status, nausea and vomiting, seizures, and cerebral edema which is also referred to as exertional hyponatremia encephalopathy. ${ }^{15,43,55}$ Other signs and symptoms can include puffiness, body weight gain from baseline or weight-in, and lightheadedness. ${ }^{55}$ Treatment of exertional hyponatremia include activation of the EAP with altered mental state to receive intravenous hypertonic saline during transportation or at the emergency department. ${ }^{15,55}$ If exertional hyponatremia is suspected, vitals should be measured. ${ }^{56}$ It will be treated with hypertonic saline IV to reduce the risk of cerebral edema or oral hypertonic saline which could also include salty foods. ${ }^{43,55,56}$ Return to play should include individualized hydration plan and sweat testing to prevent further episodes. ${ }^{15,55,56}$

Figure B3. Prevention of Exertional Hyponatremia with Recommended Fluid Intake Strategy. ${ }^{55}$

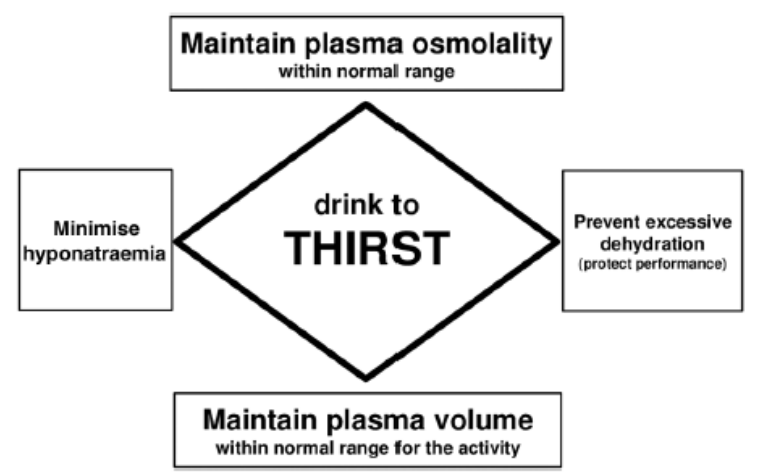

\section{Exertional Sickling}

Exertional sickling is a medical emergency that occurs in athletes with sickle cell trait, the genetic inheritance of the sickle cell trait which is one gene of sickle hemoglobin and one for normal hemoglobin of red blood cells. ${ }^{15,16,79,80,95}$ This altered gene can cause a "logjam" in blood vessels which leads to ischemic rhabdomyolysis and sickling collapse during intense exercise. ${ }^{37}$ 57,79,80,95 Sickle cell trait is commonly found in African, Mediterranean, Middle Eastern, Asian, or Caribbean ancestry. ${ }^{57,96,97}$ Newborn testing is required in all states but must be communicated and listed. ${ }^{57,96}$ Harmon et al ${ }^{97}$ examined NCAA student-athlete deaths, discovering five sickle 
cell trait associated deaths from 2004-2008. All five deaths were in black Division I football athletes. ${ }^{97}$ From 1999-2010, Boden et al ${ }^{37}$ cited eleven deaths (two high school and nine college football athletes) from complications related to sickle cell trait.

Prevention of exertional sickling includes proper screening for sickle cell trait and precautions with athletes who possess the gene. ${ }^{15}$ Athletes with sickle cell trait should cease exercise immediately when developing symptoms and utilize a slow-buildup for conditioning. ${ }^{24,57,79,96}$ Signs and symptoms of exertional sickling are comprised of sudden collapse, muscle cramping without twinges and pain, swelling, weakness, tenderness, inability to catch his or her breath, and fatigue. ${ }^{15,57,79,80}$ Symptoms are directly related to exercise intensity and may begin with five minutes of exercise. ${ }^{57,79,80}$ Exertional sickling athletes should be transported to an emergency department and activation of the EAP should commence. Administering high-flow oxygen and monitoring of vital signs is important until the athlete is transported to reduce the amount of sickled hemoglobin and reduce a logjam in vital organs. ${ }^{15,16,79}$ The athlete can also be cooled to reduce symptoms. ${ }^{80,96}$ Athletes who carry the sickle cell trait must communicate the diagnosis on pre-participation examinations to athletic trainers (or other health care provider) and coaches. ${ }^{24,79,80}$ Coaches should be educated in recognizing and treating an athlete experiencing exertional sickling to properly identify the collapse from other conditions and reduce the risk of sudden death. ${ }^{24,57,80}$ Return to play after exertional sickling should be gradual with special considerations for intense exercise and conditioning. $56,79,80$

\section{Head-Down Contact in Football}


It is estimated 1.1 million athletes participate in high school tackle football annually. ${ }^{61}$ From the years 2005-2014, twenty-two of twenty-four high school football fatalities involved head or brain injuries. ${ }^{61}$ Additionally, seventeen of twenty-four high school fatalities involved tackling or being tackled and eight of twenty-eight college fatalities identified head first/head down contact. ${ }^{61}$ Head-down contact in football causes an axial load to occur in the spine which can cause cervical spine fractures and dislocations leading to damage of the spinal cord. ${ }^{15,73}$ It is defined as initiating contact with the crown of the helmet which results in an axial loading of the neck that can cause a cervical spine injury. ${ }^{15,74}$ Injury to cervical vertebrae above C4 increases risk of sudden death. ${ }^{15,73}$ However, paralysis and brain damage can also occur after the mechanism of head-down contact. ${ }^{66}$ Spearing is the act of intentional head-down contact to perform a tackle which can result in axial loading and in-turn catastrophic injury. ${ }^{15}$ In 1976 , rule changes were implemented that eliminated the use of head or face for initial contact during blocking or tackling which reduced the occurrence of football catastrophic injuries. ${ }^{15,16,66,92}$ Prevention of axial loading involves proper education when initiating contact during football. The tackling position with the head up and leading with the shoulder is the safest position to contact another athlete to be able to see where they are contacting the opponent. ${ }^{15,66,73}$ The neck musculature, cervical facet joints, and intervertebral discs can absorb the force associated with the tackle. ${ }^{15}$ Coaches should practice proper tackling techniques at the beginning of the season to prevent injuries and reduce a rule violation of spearing during games. ${ }^{15,73}$ If athletes continue to practice improper tackling with the head down, coaches should be provided additional coaching and practice time attention. ${ }^{15,66}$ The CDC provides educational courses online as well as information regarding the "Heads Up" program to increase awareness of concussion in sport. ${ }^{84}$ It must be made aware that football helmets and other football equipment 
do not prevent axial loading injuries or other brain injuries as they protect against skull fractures. ${ }^{15,16,73}$ Furthermore, proper equipment fitting can ensure the equipment will properly meet the guidelines and national certification standards from the National Operating committee on Standards for Athletic Equipment (NOCSAE) for football helmets. ${ }^{15,16,66,74}$ Additionally, coaches, equipment managers, and health care professionals should possess multiple tools to remove equipment and gain access to an airway. ${ }^{74}$ Treatment for head-down contact in football injuries will follow cervical spine injury treatment and transportation for athletes with a suspected catastrophic injury. ${ }^{15,51,73}$

It is recommended that any secondary school who organizes contact or collision sports should employ an athletic trainer to provide care especially in the event of a catastrophic injury. ${ }^{15,74}$ Cantu et al ${ }^{66}$ suggested athletic trainers or medical staff should determine care and coaches should never be involved in medical decisions for head or spine injuries for athletes. In the state of West Virginia, athletic trainers or licensed health care professionals, known as limited football trainers, must be present for all high school football practices, scrimmages, and games to ensue. $^{28}$

Lightning

Lightning is a natural phenomenon which is the most dangerous natural hazard and can occur from cloud to cloud and from cloud to ground. ${ }^{15,62}$ From 2003-2012, United States lightning-related deaths were an average of 35-47 per year. ${ }^{98,99}$ Fifteen-thirty percent of lightning fatalities were during recreational activities and sporting activities. ${ }^{63}$ The negatively charged ionized gas which is built up within clouds and is attracted to positively charged regions which can include people, houses, and trees. ${ }^{15,62}$ The most frequent weather hazard surrounding athletics, lightning can strike athletes as well as spectators in an outdoor stadium or field. ${ }^{99}$ 
Prevention of lightning-related injuries or fatalities should promote National Weather Service slogans such as "No Place Outside Is Safe When Thunderstorms Are In The Area" and "When Thunder Roars, Go Indoors." ${ }^{, 62,63,98}$ If thunderstorms occur with lightning observed and thunder heard, all outdoor athletic events should be suspended and proceed to lightning-safe facilities. ${ }^{62,63}$ Individuals should stay indoors for at least 30 minutes after the last lightning observed. ${ }^{15,62}$ Play may resume after the 30 minutes yet if additional lightning strikes or thunder sounds, the 30 minute clock restarts. ${ }^{62,63}$ Also, if the lightning has not been observed but a warning is given by a weather service it is recommended to suspend outdoor activities. ${ }^{63}$ If an athlete or individual is struck by lightning, they are safe to treat immediately and should focus on the cardiorespiratory status involving CPR or AED use if necessary. ${ }^{15,62}$ Consciousness level, vitals, and deformities should be assessed immediately for a lightning victim. ${ }^{62}$ However, the safety of the scene must be ensured prior to care of a victim. ${ }^{62,53}$ The EAP should be activated and should be evaluated by a health care professional to rule out additional medical concerns such as fractures, dislocations, or shock. ${ }^{15,62}$

Sudden Cardiac Arrest

Sudden cardiac arrest can lead to sudden cardiac death which is the leading cause of death in active, young athletes. ${ }^{15}$ It is the leading cause of exercise-related fatalities in young athletes. ${ }^{46}$ The NCAA reported the incidence rate of sudden cardiac death to be $1: 43,000$ annually. ${ }^{45}$ Often, a structural cardiac abnormality, such as hypertrophic cardiomyopathy and coronary artery anomalies, is the cause of sudden cardiac arrest. ${ }^{15}$ Other causes of sudden cardiac arrest include commotio cordis, myocarditis, Marfan syndrome, and electrical disorders. ${ }^{15,100}$ Hypertrophic cardiomyopathy comprises $25 \%$ to $36 \%$ of all sudden cardiac death in the United States that occurs due to a structural cardiac anomaly in the left ventricle wall. ${ }^{82,100}$ There 
may be obstructed and nonobstructive types dependent on which valves are affected. Commotio cordis is caused by a non-penetrating force to the chest that causes a ventricular arrythmia. ${ }^{82}$ It occurs in a structurally normal heart and comprises $20 \%$ of sudden cardiac death cases for adolescent athletes. ${ }^{82}$ Myocarditis is a nonischemic heart disease and accounts for $6 \%$ of sudden cardiac deaths in young competitive athletes. ${ }^{102}$ Marfan syndrome can be diagnosed with a physical examination such as a preparticipation exam. ${ }^{46}$ This condition affects 1 in 5,000 people and affects the body's connective tissue and causes aortic enlargement. ${ }^{103}$ The condition is Electrical disorders may consist of tachycardias such as Wolff-Parkinson-White pattern and syndrome and Long QT syndrome. ${ }^{102}$ These conditions can be detected on an electrocardiogram. ${ }^{102}$

Preparticipation screening can prevent sudden cardiac arrest, however it is debated due to accuracy and cost. ${ }^{15,16}$ It has been cited that $80 \%$ of athletes with sudden cardiac death were asymptomatic until death. ${ }^{15,82,100,101}$ Nevertheless, a comprehensive personal history, family history, and physical examination can be instrumental in a preparticipation screening to detect a structural abnormality. ${ }^{9,15,100,101}$ Also, athletes who experience cardiovascular symptoms should be evaluated by a physician and receive clearance prior to return to sport. ${ }^{16}$ Symptoms include exertional chest pain, excessive shortness of breath, palpitations, exertional syncope, or exertional fatigue. $^{16}$

It is imperative to be prepared for sudden cardiac arrest through the use and access to an AED. ${ }^{15,16,20,82}$ If an athlete collapses without trauma prior, sudden cardiac arrest should be a differential until airway, breathing, and circulation is found to be within normal limits. ${ }^{15,46,82}$ CPR should be administered immediately if the athlete is unresponsive with rapid application of the AED and activation of the EAP..$^{9,15,45,46,100}$ It is recommended to administer a shock from the 
AED within 3-5 minutes from time of collapse. ${ }^{15,16,45,100}$ It is suggested the AED should be placed in a central location of facilities to decrease the distance from the specific venue location. ${ }^{101}$ Detection of sudden cardiac arrest, beginning CPR, activation of emergency medical services and the EAP, and AED use increase survival rate dramatically. ${ }^{15}$ Increased availability of an AED and EAP can increase survival rates. ${ }^{15,45,101}$ The AED should be applied as soon as possible to determine cardiac rhythm analysis. ${ }^{15,16} \mathrm{CPR}$ should only cease for rhythm analysis by the AED and defibrillation. ${ }^{15,16} \mathrm{CPR}$ should continue until arrival of emergency medical services. ${ }^{15}$ Finally, it is suggested all coaches should be certified in CPR/AED. ${ }^{6,24,64}$ Summary

Coaches in the secondary school setting may be required to recognize sudden death conditions in the absence of an athletic trainer or licensed health care professional. The NATA urges coaches to be trained and certified in CPR/AED to maximize sudden cardiac arrest survival rates. In the state of West Virginia, coaches must complete CPR/AED certification however only non-WVDE certified teachers must complete a first aid section within the WVSSAC Coaching Course. The EAP should be developed for an athletics program. It should be venue-specific, coordinated with involved personnel, and practiced annually. Athletic trainers are educated in sudden death conditions in athletics. Athletic trainers have provided education and prevention methods for sudden death conditions in athletics for athletic populations. The ten sudden death conditions include asthma, catastrophic brain injuries, cervical spine injuries, diabetes, exertional heat stroke, exertional hyponatremia, exertional sickling, head-down contact in football, lightning, and sudden cardiac arrest. The condition explained are commonly observed in athletes and is imperative that secondary school coaches are adequately prepared to handle a medical emergency. 
Table C1. Cover Letter

\section{WestVurginiaUniversity.}

Dear Participant,

This letter is a request for you to take part in a research project to determine if West Virginia Secondary School Activities Commission (WVSSAC) coaches are aware and prepared for sudden death conditions. The study will also research the availability and use of an emergency action plan (EAP) for athletics. This project is being conducted by Jillian Sarm, LAT, ATC under the supervision of Dr. Michelle A. Sandrey, PhD, ATC, an associate professor in the College of Physical Activity and Sport Sciences, for a Master's Degree in Athletic Training. Your participation in this research project is greatly appreciated and will take approximately 15 minutes to complete out the attached questionnaire.

Link to Questionnaire: https://wvu.qualtrics.com/jfe/form/SV_554XJpTJKgTDRnD

Your involvement in this project will be kept as confidential as legally possible. All data will be reported in the aggregate. You must be 18 years of age or older to participate. I will not ask any information that should lead back to your identity as a participant. Your participation is completely voluntary. You may skip any question that you do not wish to answer and you may discontinue at any time. West Virginia University's Institutional Review Board acknowledgement of this project is on file.

I hope that you will participate in this research project, as it could be beneficial in understanding the preparedness of coaches regarding sudden death conditions. Thank you very much for your time. Should you have any questions about this letter or the research project, please feel free to contact Jillian Sarm at (215) 767-5044 or by e-mail at jms0122@ mix.wvu.edu or the Principle Investigator Dr. Michelle A. Sandrey through email at msandrey@wvu.edu.

Thank you for your time and help with this project.

Sincerely,

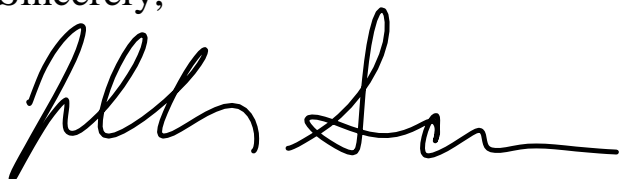

Jillian Sarm, LAT, ATC

Chestnut Ridge Research Building

Phone: 304-293-7073 886 Chestnut Ridge Road

Fax: 304-293-3098 PO Box 6845

http://oric.research.wvu.edu Morgantown, WV 26506-6845 
Dear Participant,

This letter is a follow-up request for you to take part in a research project to determine if West Virginia Secondary School Activities Commission (WVSSAC) coaches are aware and prepared for sudden death conditions. The study will also research the availability and use of an emergency action plan (EAP) for athletics. This project is being conducted by Jillian Sarm, LAT, ATC under the supervision of Dr. Michelle A. Sandrey, PhD, ATC, an associate professor in the College of Physical Activity and Sport Sciences, for a Master's Degree in Athletic Training. Your participation in this research project is greatly appreciated and will take approximately 15 minutes to complete out the attached questionnaire.

Link to Questionnaire: https://wvu.qualtrics.com/jfe/form/SV_554XJpTJKgTDRnD

Your involvement in this project will be kept as confidential as legally possible. All data will be reported in the aggregate. You must be 18 years of age or older to participate. I will not ask any information that should lead back to your identity as a participant. Your participation is completely voluntary. You may skip any question that you do not wish to answer and you may discontinue at any time. West Virginia University's Institutional Review Board acknowledgement of this project is on file.

I hope that you will participate in this research project, as it could be beneficial in understanding the preparedness of coaches regarding sudden death conditions. If you have already completed this questionnaire, thank you very much for your time. Should you have any questions about this letter or the research project, please feel free to contact Jillian Sarm at (215) 767-5044 or by email at jms0122@mix.wvu.edu or the Principle Investigator Dr. Michelle A. Sandrey through email at msandrey@wvu.edu.

Thank you for your time and help with this project.

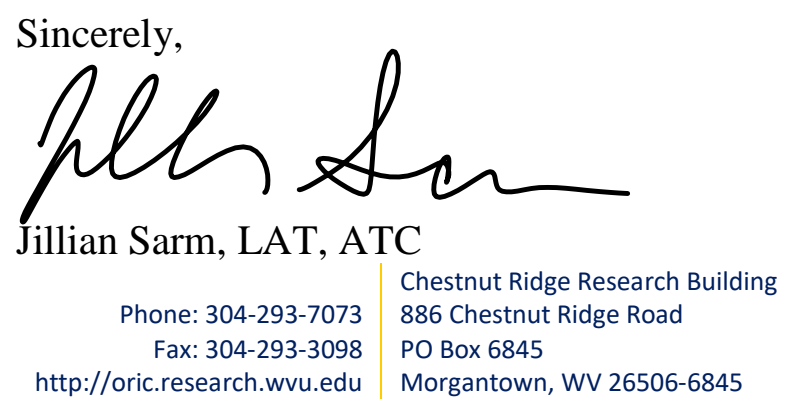


Table C3. Questionnaire

Coach Questionnaire

Part 1:

Please answer the following questions regarding the Emergency Action Plan (EAP).

Definitions:

-Emergency Action Plan - A written document which is developed and coordinated with school medical staff, school administrators, school public safety officials, local emergency medical staff, and onsite first responders that includes instructions in the event of an emergency during an athletic session. Should be specific to each athletic venue and be practiced at least annually with all involved parties.

-Emergency Action Plan Worksheet - Student Response Team- A written document provided by the WVSSAC required to be completed by each school and sport team each year. Documents are uploaded and submitted to the WVSSAC School Management Page.

1. Does your school have an Emergency Action Plan (EAP) for secondary school athletics?

$\square$ Yes $\square$ No

2. Has your school completed the "Emergency Action Plan Worksheet - Student Response Team" form which is provided by the WVSSAC?

$\square$ Yes $\square$ No

\section{Part 2:}

Directions: For following questions, please check yes or no for the sudden death conditions.

3. As a coach, are you aware of the sudden death condition?

\begin{tabular}{|l|l|l|}
\hline & Yes & No \\
\hline Asthma & & \\
\hline Catastrophic Brain Injuries & & \\
\hline Cervical Spine Injuries & & \\
\hline Diabetes & & \\
\hline Exertional Heat Stroke & & \\
\hline Exertional Hyponatremia & & \\
\hline Exertional Sickling & & \\
\hline Head-Down Contact in Football & & \\
\hline Lightning & & \\
\hline Sudden Cardiac Arrest & & \\
\hline
\end{tabular}


4. As a coach, are you prepared to provide care for an athlete experiencing the sudden death condition until EMS arrives?

\begin{tabular}{|l|l|l|}
\hline & Yes & No \\
\hline Asthma & & \\
\hline Catastrophic Brain Injuries & & \\
\hline Cervical Spine Injuries & & \\
\hline Diabetes & & \\
\hline Exertional Heat Stroke & & \\
\hline Exertional Hyponatremia & & \\
\hline Exertional Sickling & & \\
\hline Head-Down Contact in Football & & \\
\hline Lightning & & \\
\hline Sudden Cardiac Arrest & & \\
\hline
\end{tabular}

5. As a coach, have you ever provided care during a situation where an athlete experienced a sudden death condition? If the Emergency Action Plan (EAP) was activated for the situation, please check in the "EAP Activated" box.

\begin{tabular}{|l|l|l|l|}
\hline & Yes & No & EAP Activated \\
\hline Asthma & & & \\
\hline Catastrophic Brain Injuries & & & \\
\hline Cervical Spine Injuries & & & \\
\hline Diabetes & & & \\
\hline Exertional Heat Stroke & & & \\
\hline Exertional Hyponatremia & & & \\
\hline Exertional Sickling & & & \\
\hline Head-Down Contact in Football & & & \\
\hline Lightning & & & \\
\hline Sudden Cardiac Arrest & & & \\
\hline
\end{tabular}

Part 3: Demographics

Directions: Please complete the following section by selecting a response or filling in the blanks as requested.

6. What is your gender?

$\square$ Male $\quad \square$ Female

7. What is the highest level of education you have completed

$\square$ Some High School $\square$ High School degree or equivalent $\square$ Associate's Degree $\square$ Bachelor's Degree $\square$ Graduate Degree $\square$ Other 
8. Is your paid occupation a teacher at a West Virginia Department of Education school?

$\square$ Yes $\square$ No

9. How many years have you been coaching?

$\square_{0-5} \square_{6-10} \square_{11-15} \square_{16-20} \square_{21+}$

10. How many years of coaching experience do you have in high school?

$\square<$ 1year $\square_{1-4 \text { years }} \square_{5-9}$ years $\square_{10-20 \text { years }} \square_{21+\text { years }}$

11. What WVSSAC classification is the high school you currently coach at?

$\square$ A $\square$ AA $\square$ AAA

12. What high school sport(s) do you coach? Check all that apply and your position within each sport. If the sport is not listed, please check other and list specific sport.

Head Coach:

$\square_{\text {Baseball }} \square_{\text {Basketball }} \square_{\text {Cheerleading }} \square_{\text {Cross Country }} \square_{\text {Football }} \square_{\text {Golf }} \square_{\text {Soccer }} \square$

Softball $\square$ Swimming \& Diving $\square$ Tennis $\square$ Track \& Field $\square$ Volleyball $\square$ Wrestling

$\square$ Other

Assistant Coach:

$\square$ Baseball $\square$ Basketball $\square$ Cheerleading $\square_{\text {Cross Country }} \square_{\text {Football }} \square$ Golf $\square$ Soccer $\square$ Softball $\square$ Swimming \& Diving $\square$ Tennis $\square_{\text {Track \& Field }} \square_{\text {Volleyball }} \square_{\text {Wrestling }}$

$\square$ Other

Volunteer Coach:

$\square$ Baseball $\square$ Basketball $\square$ Cheerleading $\square_{\text {Cross Country }} \square_{\text {Football }} \square$ Golf $\square$ Soccer $\square$ Softball $\square$ Swimming \& Diving $\square$ Tennis $\square$ Track \& Field $\square$ Volleyball $\square$ Wrestling $\square$ Other 
13. Are you currently First Aid/CPR/AED certified?

$\square_{\text {Yes }} \square_{\text {No }} \square_{\text {Not Sure }}$

14. Have you taken the WVSSAC Coaching Course?

$\square$ Yes $\square_{\text {No }}$

15. Did you take online NFHS courses in recognizing concussions, heat illness, or sudden cardiac arrest prior to beginning coaching within the past 12 months?

$\square$ Yes $\square$ No $\square$ Not Sure

16. Who is the health care provider for your secondary school's athletics?

$\square$ Certified Athletic Trainer $\square$ Physician $\square$ Registered Nurse $\square$ Licensed Practical Nurse

$\square$ Chiropractor $\square$ Physical Therapist $\square$ Occupational Therapist $\square$ Physician's Assistant

$\square$ Paramedic $\square$ Emergency Medical Technician (EMT) $\square$ Other __ $\square$ None

Thank you for your participation! 


\section{APPENDIX D}

Table D1. Level of Education

\section{ADDITIONAL RESULTS}

\begin{tabular}{ll}
\hline Highest Level of Education & Percent $(\mathrm{N}=228)$ \\
\hline High School Degree or Equivalent & $7.9 \%(\mathrm{n}=18)$ \\
Associate's Degree & $3.9 \%(\mathrm{n}=9)$ \\
Bachelor's Degree & $32.5 \%(\mathrm{n}=47)$ \\
Graduate Degree & $50.0 \%(\mathrm{n}=114)$ \\
Other & $1.3 \%(\mathrm{n}=3)$ \\
\hline
\end{tabular}

Table D2. Total Years of Coaching

\begin{tabular}{ll}
\hline Years Coaching & Percent $(\mathrm{N}=228)$ \\
\hline $0-5$ & $25.4 \%(\mathrm{n}=58)$ \\
$6-10$ & $19.7(\mathrm{n}=45)$ \\
$11-15$ & $16.2 \%(\mathrm{n}=37)$ \\
$16-20$ & $13.2(\mathrm{n}=30)$ \\
$21+$ & $20.6 \%(\mathrm{n}=47)$ \\
\hline
\end{tabular}

Table D3. Years Coaching at the High School Level

\begin{tabular}{ll}
\hline Years Coaching at High School & Percent $(\mathrm{N}=228)$ \\
\hline$<1$ & $11.0 \%(\mathrm{n}=25)$ \\
$1-4$ & $24.6 \%(\mathrm{n}=56)$ \\
$5-9$ & $20.2 \%(\mathrm{n}=46)$ \\
$10-20$ & $25.9 \%(\mathrm{n}=59)$ \\
$21+$ & $13.6 \%(\mathrm{n}=31)$ \\
\hline
\end{tabular}

Table D4. High School Sport(s) Coaching Position

\begin{tabular}{llll}
\hline Sport & Head Coach & Assistant Coach & Volunteer Coach \\
\hline Baseball & $7.9 \%(\mathrm{n}=18)$ & $3.5 \%(\mathrm{n}=8)$ & $3.1 \%(\mathrm{n}=7)$ \\
Basketball & $10.5 \%(\mathrm{n}=24)$ & $7.5 \%(\mathrm{n}=17)$ & $1.3 \%(\mathrm{n}=3)$ \\
Cheerleading & $6.1 \%(\mathrm{n}=14)$ & $1.8 \%(\mathrm{n}=4)$ & $1.3 \%(\mathrm{n}=3)$ \\
Cross Country & $8.8 \%(\mathrm{n}=20)$ & $0.9 \%(\mathrm{n}=2)$ & $0.9 \%(\mathrm{n}=2)$ \\
Football & $9.6 \%(\mathrm{n}=22)$ & $7.0 \%(\mathrm{n}=16)$ & $1.3 \%(\mathrm{n}=3)$ \\
Golf & $2.6 \%(\mathrm{n}=6)$ & - & - \\
Soccer & $10.1 \%(\mathrm{n}=23)$ & $1.3 \%(\mathrm{n}=3)$ & $1.3 \%(\mathrm{n}=3)$ \\
Softball & $7.9 \%(\mathrm{n}=18)$ & $2.6 \%(\mathrm{n}=6)$ & $1.3 \%(\mathrm{n}=3)$ \\
Swimming \& Diving & $3.5 \%(\mathrm{n}=8)$ & $1.3 \%(\mathrm{n}=3)$ & $0.9 \%(\mathrm{n}=2)$ \\
Tennis & $5.7 \%(\mathrm{n}=13)$ & $0.9 \%(\mathrm{n}=2)$ & $0.4 \%(\mathrm{n}=1)$ \\
Track \& Field & $12.3 \%(\mathrm{n}=28)$ & $2.6 \%(\mathrm{n}=6)$ & $1.3 \%(\mathrm{n}=3)$ \\
Volleyball & $7.5 \%(\mathrm{n}=17)$ & $3.9 \%(\mathrm{n}=9)$ & $0.9 \%(\mathrm{n}=2)$ \\
Wrestling & $5.3 \%(\mathrm{n}=12)$ & $2.6 \%(\mathrm{n}=6)$ & - \\
Other & $5.7 \%(\mathrm{n}=13)$ & $1.3 \%(\mathrm{n}=3)$ & $1.3 \%(\mathrm{n}=3)$ \\
$\quad$ & & \\
$\quad$ Athletic Director & & & \\
\hline
\end{tabular}


Table D5. Coaching Certifications and Courses

\begin{tabular}{llll}
\hline Coaching Courses & Yes & No & Not sure \\
\hline First Aid/CPR/AED & $56.1 \%(\mathrm{n}=128)$ & $31.6 \%(\mathrm{n}=72)$ & $3.9 \%(\mathrm{n}=9)$ \\
WVSSAC Coaching Course & $59.6 \%(\mathrm{n}=136)$ & $32.0 \%(\mathrm{n}=73)$ & - \\
NFHS: Concussion, Heat & $89.0 \%(\mathrm{n}=203)$ & $1.8 \%(\mathrm{n}=4)$ & $0.9 \%(\mathrm{n}=2)$ \\
Illness, Sudden Cardiac Arrest & & & \\
\hline
\end{tabular}

Table D6. Health Care Provider

\begin{tabular}{ll}
\hline Health Care Provider & Percent $(\mathrm{N}=228)$ \\
\hline Certified Athletic Trainer & $57.5 \%(\mathrm{n}=131)$ \\
Physician & $7.9 \%(\mathrm{n}=18)$ \\
Registered Nurse & $7.5 \%(\mathrm{n}=17)$ \\
Licensed Practical Nurse & - \\
Chiropractor & $1.8 \%(\mathrm{n}=4)$ \\
Physical Therapist & $2.6 \%(\mathrm{n}=6)$ \\
Occupational Therapist & - \\
Physician's Assistant & $2.2 \%(\mathrm{n}=5)$ \\
Paramedic & $4.8 \%(\mathrm{n}=11)$ \\
Emergency Medical Technician (EMT) & $9.2 \%(\mathrm{n}=21)$ \\
Other & $4.4 \%(\mathrm{n}=10)$ \\
$\quad$ AT for Football & \\
$\quad$ Infirmary & \\
$\quad$ State Certified AT & \\
$\quad$ LPN and EMT Parent & \\
$\quad$ None & \\
None & \\
\hline
\end{tabular}

Table D7. Coaches' Awareness of Sudden Death Conditions in Athletics

\begin{tabular}{lll}
\hline Condition & Yes & No \\
\hline Asthma & $90.4 \%(\mathrm{n}=206)$ & $5.7 \%(\mathrm{n}=13)$ \\
Catastrophic Brain Injuries & $88.2 \%(\mathrm{n}=201)$ & $7.0 \%(\mathrm{n}=16)$ \\
Cervical Spine Injuries & $83.3 \%(\mathrm{n}=190)$ & $11.4 \%(\mathrm{n}=26)$ \\
Diabetes & $82.9 \%(\mathrm{n}=189)$ & $12.7 \%(\mathrm{n}=29)$ \\
Exertional Heat Stroke & $96.1 \%(\mathrm{n}=219)$ & $0.9 \%(\mathrm{n}=2)$ \\
Exertional Hyponatremia & $58.8 \%(\mathrm{n}=134)$ & $35.1 \%(\mathrm{n}=80)$ \\
Exertional Sickling & $46.9 \%(\mathrm{n}=107)$ & $47.8 \%(\mathrm{n}=109)$ \\
Head-Down Contact in Football & $78.9 \%(\mathrm{n}=180)$ & $16.2 \%(\mathrm{n}=37)$ \\
Lightning & $93.4 \%(\mathrm{n}=213)$ & $2.2 \%(\mathrm{n}=5)$ \\
Sudden Cardiac Arrest & $94.7 \%(\mathrm{n}=216)$ & $1.8 \%(\mathrm{n}=4)$ \\
\hline
\end{tabular}


Table D8. Coaches' Preparedness of Sudden Death Conditions in Athletics

\begin{tabular}{lll}
\hline Condition & Yes & No \\
\hline Asthma & $83.3 \%(\mathrm{n}=190)$ & $11.0 \%(\mathrm{n}=25)$ \\
Catastrophic Brain Injuries & $66.7 \%(\mathrm{n}=152)$ & $26.3 \%(\mathrm{n}=60)$ \\
Cervical Spine Injuries & $68.0 \%(\mathrm{n}=155)$ & $25.4 \%(\mathrm{n}=58)$ \\
Diabetes & $75.9 \%(\mathrm{n}=173)$ & $17.1 \%(\mathrm{n}=39)$ \\
Exertional Heat Stroke & $90.8 \%(\mathrm{n}=207)$ & $4.8 \%(\mathrm{n}=11)$ \\
Exertional Hyponatremia & $52.2 \%(\mathrm{n}=119)$ & $39.9 \%(\mathrm{n}=91)$ \\
Exertional Sickling & $39.0 \%(\mathrm{n}=89)$ & $52.6 \%(\mathrm{n}=120)$ \\
Head-Down Contact in Football & $65.4 \%(\mathrm{n}=149)$ & $27.2 \%(\mathrm{n}=62)$ \\
Lightning & $77.6 \%(\mathrm{n}=177)$ & $16.2 \%(\mathrm{n}=16)$ \\
Sudden Cardiac Arrest & $87.3 \%(\mathrm{n}=199)$ & $7.0 \%(\mathrm{n}=16)$ \\
\hline
\end{tabular}

Table D9. Coaches' Provision of Care for Sudden Death Conditions and Activation of the Emergency Action Plan (EAP)

\begin{tabular}{llll}
\hline Condition & Yes & No & EAP Activated \\
\hline Asthma & $19.3 \%(\mathrm{n}=44)$ & $75.9 \%(\mathrm{n}=173)$ & $3.9 \%(\mathrm{n}=9)$ \\
Catastrophic Brain Injuries & $5.3 \%(\mathrm{n}=12)$ & $89.5 \%(\mathrm{n}=204)$ & $3.5 \%(\mathrm{n}=8)$ \\
Cervical Spine Injuries & $5.3 \%(\mathrm{n}=12)$ & $89.0 \%(\mathrm{n}=203)$ & $4.8 \%(\mathrm{n}=11)$ \\
Diabetes & $11.8 \%(\mathrm{n}=27)$ & $83.9 \%(\mathrm{n}=191)$ & $1.3 \%(\mathrm{n}=3)$ \\
Exertional Heat Stroke & $8.3 \%(\mathrm{n}=19)$ & $86.4 \%(\mathrm{n}=197)$ & $5.3 \%(\mathrm{n}=12)$ \\
Exertional Hyponatremia & $0.9 \%(\mathrm{n}=2)$ & $93.4 \%(\mathrm{n}=213)$ & $1.3 \%(\mathrm{n}=3)$ \\
Exertional Sickling & $0.9 \%(\mathrm{n}=2)$ & $92.5 \%(\mathrm{n}=211)$ & $2.2 \%(\mathrm{n}=5)$ \\
Head-Down Contact in Football & $8.8 \%(\mathrm{n}=20)$ & $85.5 \%(\mathrm{n}=195)$ & $5.7 \%(\mathrm{n}=13)$ \\
Lightning & $9.6 \%(\mathrm{n}=22)$ & $82.9 \%(\mathrm{n}=189)$ & $6.6 \%(\mathrm{n}=15)$ \\
Sudden Cardiac Arrest & $1.8 \%(\mathrm{n}=4)$ & $92.1 \%(\mathrm{n}=210)$ & $1.8 \%(\mathrm{n}=4)$ \\
\hline
\end{tabular}

Table D10. Health Care Provider and Availability of the EAP

\begin{tabular}{llll}
\hline Health Care Provider & Yes & No & $\chi^{2}{ }_{1,228}$ \\
\hline Certified Athletic Trainer & $63.5 \%(\mathrm{n}=129)$ & $1.0 \%(\mathrm{n}=2)$ & $\chi^{2}{ }_{1,228}=1.110$, \\
Physician & $4.9 \%(\mathrm{n}=10)$ & - & $\mathrm{P}=0.999, \mathrm{cc}=0.074$ \\
Registered Nurse & $5.4 \%(\mathrm{n}=11)$ & - & \\
Chiropractor & $0.5 \%(\mathrm{n}=1)$ & - & \\
Physical Therapist & $1.0 \%(\mathrm{n}=2)$ & - & \\
Physician's Assistant & $1.0 \%(\mathrm{n}=2)$ & - & \\
Paramedic & $3.9 \%(\mathrm{n}=8)$ & - & \\
EMT & $4.4 \%(\mathrm{n}=9)$ & - & \\
Other & $3.9 \%(\mathrm{n}=8)$ & - & \\
None & - & - & \\
\hline
\end{tabular}

Key: $\chi^{2}=$ Pearson Chi Square 
Table D11. Health Care Provider and Prepared to Provide Care for Asthma

\begin{tabular}{llll}
\hline Health Care Provider & Yes & No & $\chi^{2} 1,228$ \\
\hline Certified Athletic Trainer & $58.4 \%(\mathrm{n}=115)$ & $6.6 \%(\mathrm{n}=13)$ & $\chi^{2}{ }_{1,228}=23.621^{*}$, \\
Physician & $5.1 \%(\mathrm{n}=10)$ & - & $\mathrm{P}=0.005, \mathrm{cc}=0.327$ \\
Registered Nurse & $5.1 \%(\mathrm{n}=10)$ & - & \\
Chiropractor & - & $0.51 \%(\mathrm{n}=1)$ & \\
Physical Therapist & $0.51 \%(\mathrm{n}=1)$ & $0.51 \%(\mathrm{n}=1)$ & \\
Physician's Assistant & $0.51 \%(\mathrm{n}=1)$ & $0.51 \%(\mathrm{n}=1)$ & \\
Paramedic & $4.1 \%(\mathrm{n}=8)$ & - & \\
EMT & $4.6 \%(\mathrm{n}=9)$ & - & \\
Other & $4.1 \%(\mathrm{n}=8)$ & - & \\
None & $6.6 \%(\mathrm{n}=13)$ & $2.5 \%(\mathrm{n}=5)$ & \\
\hline
\end{tabular}

Key: $\chi^{2}=$ Pearson Chi Square; * significant finding at $\mathrm{P}<.05$

Table D12. Health Care Provider and Prepared to Provide Care for Catastrophic Brain Injuries

\begin{tabular}{llll}
\hline Health Care Provider & Yes & No & $\chi^{2} 1,228$ \\
\hline Certified Athletic Trainer & $49.2 \%(\mathrm{n}=96)$ & $15.9 \%(\mathrm{n}=31)$ & $\chi^{2} 1,228=10.886$, \\
Physician & $2.5 \%(\mathrm{n}=5)$ & $2.5 \%(\mathrm{n}=5)$ & $\mathrm{P}=0.284, \mathrm{cc}=0.230$ \\
Registered Nurse & $4.1 \%(\mathrm{n}=8)$ & $1.0 \%(\mathrm{n}=2)$ & \\
Chiropractor & $0.5 \%(\mathrm{n}=1)$ & $0.5 \%(\mathrm{n}=1)$ & \\
Physical Therapist & $0.5 \%(\mathrm{n}=1)$ & $0.5 \%(\mathrm{n}=1)$ & \\
Physician's Assistant & - & $1.0 \%(\mathrm{n}=2)$ & \\
Paramedic & $3.1 \%(\mathrm{n}=6)$ & $1.0 \%(\mathrm{n}=2)$ & \\
EMT & $3.6 \%(\mathrm{n}=7)$ & $1.0 \%(\mathrm{n}=2)$ & \\
Other & $3.1 \%(\mathrm{n}=6)$ & $1.0 \%(\mathrm{n}=2)$ & \\
None & $5.6 \%(\mathrm{n}=11)$ & $3.6 \%(\mathrm{n}=7)$ & 195 \\
\hline
\end{tabular}

KEY: $\chi^{2}=$ Pearson Chi Square

Table D13. Health Care Provider and Prepared to Provide Care for Cervical Spine Injuries

\begin{tabular}{llll}
\hline Health Care Provider & Yes & No & $\chi^{2}{ }_{1,228}$ \\
\hline Certified Athletic Trainer & $49.0 \%(\mathrm{n}=96)$ & $16.3 \%(\mathrm{n}=32)$ & $\chi^{2}{ }_{1,228}=5.002$, \\
Physician & $2.6 \%(\mathrm{n}=5)$ & $2.6 \%(\mathrm{n}=5)$ & $\mathrm{P}=0.834, \mathrm{cc}=0.158$ \\
Registered Nurse & $4.1 \%(\mathrm{n}=8)$ & $1.0 \%(\mathrm{n}=2)$ & \\
Chiropractor & $0.5 \%(\mathrm{n}=1)$ & - & \\
Physical Therapist & $0.5 \%(\mathrm{n}=1)$ & $0.5 \%(\mathrm{n}=1)$ & \\
Physician's Assistant & $0.5 \%(\mathrm{n}=1)$ & $0.5 \%(\mathrm{n}=1)$ & \\
Paramedic & $3.1 \%(\mathrm{n}=6)$ & $1.0 \%(\mathrm{n}=2)$ & \\
EMT & $3.6 \%(\mathrm{n}=7)$ & $1.0 \%(\mathrm{n}=2)$ & \\
Other & $3.1 \%(\mathrm{n}=6)$ & $1.0 \%(\mathrm{n}=2)$ & \\
None & $7.1 \%(\mathrm{n}=14)$ & $2.0 \%(\mathrm{n}=4)$ & \\
\hline
\end{tabular}

Key: $\chi^{2}=$ Pearson Chi Square 
Table D14. Health Care Provider and Prepared to Provide Care for Diabetes

\begin{tabular}{llll}
\hline Health Care Provider & Yes & No & $\chi^{2}{ }_{1,228}$ \\
\hline Certified Athletic Trainer & $53.6 \%(\mathrm{n}=104)$ & $11.9 \%(\mathrm{n}=23)$ & $\chi^{2}{ }_{1,228}=12.223$, \\
Physician & $3.1 \%(\mathrm{n}=6)$ & $2.1 \%(\mathrm{n}=4)$ & $\mathrm{P}=0.201, \mathrm{cc}=0.243$ \\
Registered Nurse & $5.2 \%(\mathrm{n}=10)$ & $0.5 \%(\mathrm{n}=1)$ & \\
Chiropractor & - & $0.5 \%(\mathrm{n}=1)$ & \\
Physical Therapist & $0.5 \%(\mathrm{n}=1)$ & $0.5 \%(\mathrm{n}=1)$ & \\
Physician's Assistant & $1.0 \%(\mathrm{n}=2)$ & - & \\
Paramedic & $3.6 \%(\mathrm{n}=7)$ & - & \\
EMT & $4.1 \%(\mathrm{n}=8)$ & $0.5 \%(\mathrm{n}=1)$ & \\
Other & $3.6 \%(\mathrm{n}=7)$ & $0.5 \%(\mathrm{n}=1)$ & \\
None & $7.2 \%(\mathrm{n}=14)$ & $0.5 \%(\mathrm{n}=1)$ & \\
\hline
\end{tabular}

Key: $\chi^{2}=$ Pearson Chi Square

Table D15. Health Care Provider and Prepared to Provide Care for Exertional Heat Stroke

\begin{tabular}{llll}
\hline Health Care Provider & Yes & No & $\chi^{2} 1,228$ \\
\hline Certified Athletic Trainer & $62.0 \%(\mathrm{n}=124)$ & $2.5 \%(\mathrm{n}=5)$ & $\chi^{2} 1,228=7.672$, \\
Physician & $4.0 \%(\mathrm{n}=8)$ & $1.0 \%(\mathrm{n}=2)$ & $\mathrm{P}=0.568, \mathrm{c}=0.192$ \\
Registered Nurse & $5.0 \%(\mathrm{n}=10)$ & $0.5 \%(\mathrm{n}=1)$ & \\
Chiropractor & $0.5 \%(\mathrm{n}=1)$ & - & \\
Physical Therapist & $1.0 \%(\mathrm{n}=2)$ & - & \\
Physician's Assistant & $1.0 \%(\mathrm{n}=2)$ & - & \\
Paramedic & $4.0 \%(\mathrm{n}=8)$ & - & \\
EMT & $4.5 \%(\mathrm{n}=9)$ & - & \\
Other & $4.0 \%(\mathrm{n}=8)$ & - & \\
None & $9.5 \%(\mathrm{n}=19)$ & $0.5 \%(\mathrm{n}=1)$ & \\
\hline
\end{tabular}

Key: $\chi^{2}=$ Pearson Chi Square

Table D16. Health Care Provider and Prepared to Provide Care for Exertional Hyponatremia

\begin{tabular}{llll}
\hline Health Care Provider & Yes & No & $\chi^{2}{ }_{1,228}$ \\
\hline Certified Athletic Trainer & $41.5 \%(\mathrm{n}=80)$ & $23.8 \%(\mathrm{n}=46)$ & $\chi^{2}{ }_{1,228}=8.981$, \\
Physician & $3.1 \%(\mathrm{n}=6)$ & $2.1 \%(\mathrm{n}=4)$ & $\mathrm{P}=0.439, \mathrm{cc}=0.211$ \\
Registered Nurse & $3.1 \%(\mathrm{n}=6)$ & $2.1 \%(\mathrm{n}=4)$ & \\
Chiropractor & - & $0.5 \%(\mathrm{n}=1)$ & \\
Physical Therapist & $0.5 \%(\mathrm{n}=1)$ & $0.5 \%(\mathrm{n}=1)$ & \\
Physician's Assistant & $0.5 \%(\mathrm{n}=1)$ & $0.5 \%(\mathrm{n}=1)$ & \\
Paramedic & $1.6 \%(\mathrm{n}=3)$ & $2.6 \%(\mathrm{n}=5)$ & \\
EMT & $2.6 \%(\mathrm{n}=5)$ & $2.1 \%(\mathrm{n}=4)$ & \\
Other & $2.1 \%(\mathrm{n}=4)$ & $1.6 \%(\mathrm{n}=3)$ & \\
None & $3.1 \%(\mathrm{n}=6)$ & $6.2 \%(\mathrm{n}=12)$ & \\
\hline
\end{tabular}

Key: $\chi^{2}=$ Pearson Chi Square 
Table D17. Health Care Provider and Prepared to Provide Care for Exertional Sickling

\begin{tabular}{llll}
\hline Health Care Provider & Yes & No & $\chi^{2}{ }_{1,228}$ \\
\hline Certified Athletic Trainer & $32.2 \%(\mathrm{n}=62)$ & $33.3 \%(\mathrm{n}=64)$ & $\chi^{2}{ }_{1,228}=10.769$, \\
Physician & $2.1 \%(\mathrm{n}=4)$ & $3.1 \%(\mathrm{n}=6)$ & $\mathrm{P}=0.292, \mathrm{cc}=0.230$ \\
Registered Nurse & $2.1 \%(\mathrm{n}=4)$ & $3.1 \%(\mathrm{n}=6)$ & \\
Chiropractor & - & $0.5 \%(\mathrm{n}=1)$ & \\
Physical Therapist & - & $1.0 \%(\mathrm{n}=2)$ & \\
Physician's Assistant & $0.5 \%(\mathrm{n}=1)$ & $0.5 \%(\mathrm{n}=1)$ & \\
Paramedic & $1.0 \%(\mathrm{n}=2)$ & $3.1 \%(\mathrm{n}=6)$ & \\
EMT & $1.6 \%(\mathrm{n}=3)$ & $3.1 \%(\mathrm{n}=6)$ & \\
Other & $2.1 \%(\mathrm{n}=4)$ & $1.6 \%(\mathrm{n}=3)$ & \\
None & $1.6 \%(\mathrm{n}=3)$ & $7.3 \%(\mathrm{n}=14)$ & \\
\hline
\end{tabular}

Key: $\chi^{2}=$ Pearson Chi Square

Table D18. Health Care Provider and Prepared to Provide Care for Head-Down Contact in Football

\begin{tabular}{llll}
\hline Health Care Provider & Yes & No & $\chi^{2}{ }_{1,228}$ \\
\hline Certified Athletic Trainer & $49.0 \%(\mathrm{n}=95)$ & $16.5 \%(\mathrm{n}=32)$ & $\chi^{2}{ }_{1,228}=20.901^{*}$, \\
Physician & $2.1 \%(\mathrm{n}=4)$ & $3.1 \%(\mathrm{n}=6)$ & $\mathrm{P}=0.013, \mathrm{cc}=0.312$ \\
Registered Nurse & $5.2 \%(\mathrm{n}=10)$ & - & \\
Chiropractor & $0.5 \%(\mathrm{n}=1)$ & - & \\
Physical Therapist & - & $1.0 \%(\mathrm{n}=2)$ & \\
Physician's Assistant & - & $1.0 \%(\mathrm{n}=2)$ & \\
Paramedic & $3.1 \%(\mathrm{n}=6)$ & $1.0 \%(\mathrm{n}=2)$ & \\
EMT & $3.1 \%(\mathrm{n}=6)$ & $1.5 \%(\mathrm{n}=3)$ & \\
Other & $2.6 \%(\mathrm{n}=5)$ & $1.0 \%(\mathrm{n}=2)$ & \\
None & $5.7 \%(\mathrm{n}=11)$ & $3.6 \%(\mathrm{n}=7)$ & \\
\hline
\end{tabular}

Key: $\chi^{2}=$ Pearson Chi Square; $*$ significant finding at $\mathrm{P}<.05$

Table D19. Health Care Provider and Prepared to Provide Care for Lightning

\begin{tabular}{llll}
\hline Health Care Provider & Yes & No & $\chi^{2}{ }_{1,228}$ \\
\hline Certified Athletic Trainer & $54.8 \%(\mathrm{n}=108)$ & $10.7 \%(\mathrm{n}=21)$ & $\chi^{2} 1,228=9.683$, \\
Physician & $4.1 \%(\mathrm{n}=8)$ & $1.0 \%(\mathrm{n}=2)$ & $\mathrm{P}=0.377, \mathrm{cc}=0.216$ \\
Registered Nurse & $5.1 \%(\mathrm{n}=10)$ & - & \\
Chiropractor & $0.5 \%(\mathrm{n}=1)$ & - & \\
Physical Therapist & $0.5 \%(\mathrm{n}=1)$ & $0.5 \%(\mathrm{n}=1)$ & \\
Physician's Assistant & $0.5 \%(\mathrm{n}=1)$ & $0.5 \%(\mathrm{n}=1)$ & \\
Paramedic & $4.1 \%(\mathrm{n}=8)$ & - & \\
EMT & $4.1 \%(\mathrm{n}=8)$ & $0.5 \%(\mathrm{n}=1)$ & \\
Other & $4.1 \%(\mathrm{n}=8)$ & - & \\
None & $7.1 \%(\mathrm{n}=14)$ & $2.0 \%(\mathrm{n}=4)$ & \\
\hline
\end{tabular}

Key: $\chi^{2}=$ Pearson Chi Square 
Table D20. Health Care Provider and Prepared to Provide Care for Sudden Cardiac Arrest

\begin{tabular}{llll}
\hline Health Care Provider & Yes & No & $\chi^{2} 1,228$ \\
\hline Certified Athletic Trainer & $60.2 \%(\mathrm{n}=118)$ & $4.6 \%(\mathrm{n}=9)$ & $\chi^{2}{ }_{1,228}=7.634$, \\
Physician & $4.6 \%(\mathrm{n}=9)$ & $0.5 \%(\mathrm{n}=1)$ & $\mathrm{P}=0.571, \mathrm{cc}=0.194$ \\
Registered Nurse & $5.1 \%(\mathrm{n}=10)$ & $0.5 \%(\mathrm{n}=1)$ & \\
Chiropractor & $0.5 \%(\mathrm{n}=1)$ & - & \\
Physical Therapist & $1.0 \%(\mathrm{n}=2)$ & - & \\
Physician's Assistant & $0.5 \%(\mathrm{n}=1)$ & $0.5 \%(\mathrm{n}=1)$ & \\
Paramedic & $3.6 \%(\mathrm{n}=7)$ & $0.5 \%(\mathrm{n}=1)$ & \\
EMT & $4.1 \%(\mathrm{n}=8)$ & - & \\
Other & $4.1 \%(\mathrm{n}=8)$ & - & \\
None & $9.2 \%(\mathrm{n}=18)$ & $0.5 \%(\mathrm{n}=1)$ & \\
\hline
\end{tabular}

Key: $\chi^{2}=$ Pearson Chi Square

Table D21. WVSSAC Coaching Course and Preparedness for Sudden Death Conditions

\begin{tabular}{lllll}
\hline Condition & $\begin{array}{l}\text { Coaching } \\
\text { Course }\end{array}$ & $\begin{array}{l}\text { Preparedness } \\
\text { Yes }\end{array}$ & $\begin{array}{l}\text { Preparedness } \\
\text { No }\end{array}$ & $\chi^{2}{ }_{1,228}$ \\
\hline Asthma & Yes & $59.4 \%(\mathrm{n}=120)$ & $5.9 \%(\mathrm{n}=12)$ & $\chi^{2}{ }_{1,228}=1.989$, \\
& No & $29.2 \%(\mathrm{n}=59)$ & $5.4 \%(\mathrm{n}=11)$ & $\mathrm{P}=0.158, \mathrm{cc}=0.099$ \\
Catastrophic Brain & Yes & $49.7 \%(\mathrm{n}=99)$ & $15.6 \%(\mathrm{n}=31)$ & $\chi^{2}{ }_{1,228}=3.420$, \\
Injuries & No & $22.1 \%(\mathrm{n}=44)$ & $12.7 \%(\mathrm{n}=25)$ & $\mathrm{P}=0.065, \mathrm{cc}=0.130$ \\
Cervical Spine & Yes & $50.5 \%(\mathrm{n}=101)$ & $14.5 \%(\mathrm{n}=29)$ & $\chi^{2}{ }_{1,228}=3.352$, \\
Injuries & No & $23.0 \%(\mathrm{n}=46)$ & $12.0 \%(\mathrm{n}=24)$ & $\mathrm{P}=0.067, \mathrm{cc}=0.128$ \\
Diabetes & Yes & $53.3 \%(\mathrm{n}=106)$ & $11.6 \%(\mathrm{n}=23)$ & $\chi^{2}{ }_{1,228}=0.015$, \\
& No & $29.1 \%(\mathrm{n}=58)$ & $6.0 \%(\mathrm{n}=12)$ & $\mathrm{P}=0.903, \mathrm{cc}=0.009$ \\
Exertional Heat Stroke & Yes & $62.4 \%(\mathrm{n}=128)$ & $2.9 \%(\mathrm{n}=6)$ & $\chi^{2}{ }_{1,228}=0.134$, \\
& No & $32.7 \%(\mathrm{n}=67)$ & $2.0 \%(\mathrm{n}=4)$ & $\mathrm{P}=0.715, \mathrm{cc}=0.026$ \\
Exertional & Yes & $40.1 \%(\mathrm{n}=79)$ & $24.4 \%(\mathrm{n}=48)$ & $\chi^{2} 1,228=2.757$, \\
Hyponatremia & No & $17.8 \%(\mathrm{n}=35)$ & $17.8 \%(\mathrm{n}=35)$ & $\mathrm{P}=0.097, \mathrm{cc}=0.117$ \\
Exertional Sickling & Yes & $29.6 \%(\mathrm{n}=58)$ & $35.2 \%(\mathrm{n}=69)$ & $\chi^{2}{ }_{1,228}=0.778$, \\
& No & $13.8 \%(\mathrm{n}=27)$ & $21.4 \%(\mathrm{n}=42)$ & $\mathrm{P}=0.378, \mathrm{cc}=0.063$ \\
Head-Down Contact & Yes & $48.4 \%(\mathrm{n}=96)$ & $16.7 \%(\mathrm{n}=33)$ & $\chi^{2}{ }_{1,228}=1.335$, \\
in Football & No & $23.2 \%(\mathrm{n}=46)$ & $11.6 \%(\mathrm{n}=23)$ & $\mathrm{P}=0.248, \mathrm{cc}=0.081$ \\
Lightning & Yes & $56.2 \%(\mathrm{n}=113)$ & $9.0 \%(\mathrm{n}=18)$ & $\chi^{2}{ }_{1,228}=1.335$, \\
& No & $27.9 \%(\mathrm{n}=56)$ & $7.0 \%(\mathrm{n}=14)$ & $\mathrm{P}=0.248, \mathrm{cc}=0.081$ \\
Sudden Cardiac Arrest & Yes & $62.2 \%(\mathrm{n}=125)$ & $3.5 \%(\mathrm{n}=7)$ & $\chi^{2}{ }_{1,228}=1.639$, \\
& No & $30.8 \%(\mathrm{n}=62)$ & $3.5 \%(\mathrm{n}=7)$ & $\mathrm{P}=0.200, \mathrm{cc}=0.090$ \\
\hline
\end{tabular}

Key: $\chi^{2}=$ Pearson Chi Square 
Table D22. NFHS Course Completion and Preparedness for Sudden Death Conditions

\begin{tabular}{|c|c|c|c|c|}
\hline Condition & $\begin{array}{l}\text { NFHS } \\
\text { Courses }\end{array}$ & $\begin{array}{l}\text { Preparedness } \\
\text { Yes }\end{array}$ & No & $\Sigma$ \\
\hline \multirow[t]{3}{*}{ Asthma } & Yes & $85.1 \%(\mathrm{n}=172)$ & $11.9 \%(n=24)$ & \multirow[t]{3}{*}{$\Sigma=0.327, \mathrm{P}=1.000$} \\
\hline & No & $2.0 \%(\mathrm{n}=4)$ & - & \\
\hline & Not Sure & $1.0 \%(\mathrm{n}=2)$ & - & \\
\hline Catastrophic Brain & Yes & $68.8 \%(n=137)$ & $28.6 \%(n=57)$ & \multirow[t]{3}{*}{$\Sigma=1.149, \mathrm{P}=0.775$} \\
\hline \multirow[t]{2}{*}{ Injuries } & No & $1.5 \%(\mathrm{n}=3)$ & - & \\
\hline & Not Sure & $1.0 \%(n=2)$ & - & \\
\hline Cervical Spine & Yes & $70.5 \%(n=141)$ & $27.0 \%(n=54)$ & \multirow[t]{3}{*}{$\Sigma=0.991, \mathrm{P}=0.768$} \\
\hline \multirow[t]{2}{*}{ Injuries } & No & $1.5 \%(\mathrm{n}=3)$ & - & \\
\hline & Not Sure & $1.0 \%(\mathrm{n}=2)$ & - & \\
\hline \multirow[t]{3}{*}{ Diabetes } & Yes & $78.9 \%(n=157)$ & $18.1 \%(n=36)$ & \multirow[t]{3}{*}{$\Sigma=0.523, \mathrm{P}=1.000$} \\
\hline & No & $2.0 \%(\mathrm{n}=4)$ & - & \\
\hline & Not Sure & $1.0 \%(\mathrm{n}=2)$ & - & \\
\hline \multirow[t]{3}{*}{ Exertional Heat Stroke } & Yes & $91.7 \%(\mathrm{n}=188)$ & $5.4 \%(\mathrm{n}=11)$ & \multirow[t]{3}{*}{$\Sigma=0.905, \mathrm{P}=1.000$} \\
\hline & No & $2.0 \%(n=4)$ & - & \\
\hline & Not Sure & $1.0 \%(\mathrm{n}=2)$ & - & \\
\hline Exertional & Yes & $55.3 \%(\mathrm{n}=109)$ & $42.1 \%(n=83)$ & \multirow[t]{3}{*}{$\Sigma=1.334, \mathrm{P}=0.683$} \\
\hline \multirow[t]{2}{*}{ Hyponatremia } & No & $1.0 \%(\mathrm{n}=2)$ & $1.0 \%(n=1)$ & \\
\hline & Not Sure & $1.0 \%(\mathrm{n}=2)$ & - & \\
\hline \multirow[t]{3}{*}{ Exertional Sickling } & Yes & $41.3 \%(n=81)$ & $56.6 \%(n=111)$ & \multirow[t]{3}{*}{$\Sigma=2.600, \mathrm{P}=0.332$} \\
\hline & No & $0.5 \%(n=1)$ & $0.5 \%(\mathrm{n}=1)$ & \\
\hline & Not Sure & $1.0 \%(n=2)$ & - & \\
\hline \multirow{3}{*}{$\begin{array}{l}\text { Head-Down Contact } \\
\text { in Football }\end{array}$} & Yes & $68.7 \%(n=136)$ & $28.8 \%(n=57)$ & \multirow[t]{3}{*}{$\Sigma=1.164, \mathrm{P}=0.594$} \\
\hline & No & $1.5 \%(\mathrm{n}=3)$ & - & \\
\hline & Not Sure & $1.0 \%(\mathrm{n}=2)$ & - & \\
\hline \multirow[t]{3}{*}{ Lightning } & Yes & $81.1 \%(n=163)$ & $15.4 \%(n=33)$ & \multirow[t]{3}{*}{$\Sigma=0.343, \mathrm{P}=1.000$} \\
\hline & No & $1.5 \%(\mathrm{n}=3)$ & - & \\
\hline & Not Sure & $1.0 \%(n=2)$ & - & \\
\hline \multirow[t]{3}{*}{ Sudden Cardiac Arrest } & Yes & $89.6 \%(n=180)$ & $9.5 \%(n=15)$ & \multirow[t]{3}{*}{$\Sigma=0.564, \mathrm{P}=1.000$} \\
\hline & No & $2.0 \%(n=4)$ & - & \\
\hline & Not Sure & $1.0 \%(\mathrm{n}=2)$ & - & \\
\hline
\end{tabular}

Key: $\Sigma=$ Fisher's Exact Test 
Table D23. Years of Coaching Experience and Preparedness for Sudden Death Conditions

\begin{tabular}{|c|c|c|c|c|}
\hline Condition & $\begin{array}{l}\text { Years of } \\
\text { Experience }\end{array}$ & $\begin{array}{l}\text { Preparedness } \\
\text { Yes }\end{array}$ & No & $\chi^{2} 1,228$ \\
\hline \multirow[t]{5}{*}{ Asthma } & $0-5$ & $23.3 \%(\mathrm{n}=49)$ & $3.8 \%(\mathrm{n}=8)$ & \multirow[t]{5}{*}{$\Sigma=4.235, \mathrm{P}=0.370$} \\
\hline & $6-10$ & $17.6 \%(n=37)$ & $2.9 \%(n=6)$ & \\
\hline & $11-15$ & $17.1 \%(\mathrm{n}=36)$ & $0.5 \%(\mathrm{n}=1)$ & \\
\hline & $16-20$ & $11.4 \%(n=24)$ & $2.0 \%(n=4)$ & \\
\hline & $21+$ & $18.6 \%(n=39)$ & $3.0 \%(n=6)$ & \\
\hline Catastrophic Brain & $0-5$ & $18.4 \%(\mathrm{n}=38)$ & $8.7 \%(\mathrm{n}=18)$ & \multirow[t]{5}{*}{$\Sigma=2.337, \mathrm{P}=0.681$} \\
\hline \multirow[t]{4}{*}{ Injuries } & $6-10$ & $14.0 \%(n=29)$ & $6.8 \%(n=14)$ & \\
\hline & $11-15$ & $13.5 \%(n=28)$ & $3.9 \%(\mathrm{n}=8)$ & \\
\hline & $16-20$ & $9.2 \%(n=19)$ & $4.3 \%(n=9)$ & \\
\hline & $21+$ & $16.4 \%(\mathrm{n}=34)$ & $4.8 \%(\mathrm{n}=10)$ & \\
\hline Cervical Spine & $0-5$ & $19.7 \%(n=41)$ & $7.2 \%(n=15)$ & \multirow[t]{5}{*}{$\Sigma=3.271, \mathrm{P}=0.515$} \\
\hline \multirow[t]{4}{*}{ Injuries } & $6-10$ & $14.9 \%(\mathrm{n}=31)$ & $6.3 \%(n=13)$ & \\
\hline & $11-15$ & $14.4 \%(n=30)$ & $2.9 \%(n=6)$ & \\
\hline & $16-20$ & $8.7 \%(n=18)$ & $4.8 \%(n=10)$ & \\
\hline & $21+$ & $15.4 \%(\mathrm{n}=32)$ & $5.8 \%(\mathrm{n}=12)$ & \\
\hline \multirow[t]{5}{*}{ Diabetes } & $0-5$ & $22.2 \%(n=46)$ & $4.3 \%(n=9)$ & \multirow[t]{5}{*}{$\Sigma=2.087, \mathrm{P}=0.729$} \\
\hline & $6-10$ & $15.9 \%(\mathrm{n}=33)$ & $5.3 \%(\mathrm{n}=11)$ & \\
\hline & $11-15$ & $15.0 \%(n=31)$ & $2.4 \%(n=5)$ & \\
\hline & $16-20$ & $11.6 \%(n=24)$ & $1.9 \%(n=4)$ & \\
\hline & $21+$ & $17.4 \%(n=36)$ & $3.9 \%(\mathrm{n}=8)$ & \\
\hline Exertional Heat & $0-5$ & $25.3 \%(n=54)$ & $1.4 \%(\mathrm{n}=3)$ & \multirow[t]{5}{*}{$\Sigma=4.065, \mathrm{P}=0.369$} \\
\hline \multirow[t]{4}{*}{ Stroke } & $6-10$ & $20.2 \%(n=43)$ & $1 . \%(\mathrm{n}=2)$ & \\
\hline & $11-15$ & $17.4 \%(n=37)$ & - & \\
\hline & $16-20$ & $11.7 \%(n=25)$ & $1.4 \%(n=3)$ & \\
\hline & $21+$ & $20.2 \%(n=43)$ & $1.4 \%(n=3)$ & \\
\hline Exertional & $0-5$ & $17.6 \%(n=36)$ & $9.3 \%(\mathrm{n}=19)$ & \multirow[t]{5}{*}{$\Sigma=2.651, \mathrm{P}=0.622$} \\
\hline \multirow[t]{4}{*}{ Hyponatremia } & $6-10$ & $11.2 \%(n=23)$ & $10.2 \%(n=21)$ & \\
\hline & $11-15$ & $9.8 \%(n=20)$ & $7.8 \%(\mathrm{n}=16)$ & \\
\hline & $16-20$ & $6.8 \%(n=14)$ & $6.8 \%(n=14)$ & \\
\hline & $21+$ & $11.7 \%(\mathrm{n}=24)$ & $8.8 \%(\mathrm{n}=18)$ & \\
\hline \multirow[t]{5}{*}{ Exertional Sickling } & $0-5$ & $13.7 \%(n=28)$ & $12.7 \%(\mathrm{n}=26)$ & \multirow[t]{5}{*}{$\Sigma=3.272, \mathrm{P}=0.520$} \\
\hline & 6-10 & $7.4 \%(n=15)$ & $13.7 \%(\mathrm{n}=28)$ & \\
\hline & $11-15$ & $6.9 \%(n=14)$ & $10.8 \%(\mathrm{n}=22)$ & \\
\hline & $16-20$ & $6.4 \%(n=13)$ & $7.4 \%(n=15)$ & \\
\hline & $21+$ & $8.8 \%(\mathrm{n}=18)$ & $12.3 \%(\mathrm{n}=25)$ & \\
\hline Head-Down Contact & $0-5$ & $19.4 \%(n=40)$ & $7.3 \%(\mathrm{n}=15)$ & \multirow[t]{5}{*}{$\Sigma=0.701, \mathrm{P}=0.957$} \\
\hline \multirow[t]{4}{*}{ in Football } & $6-10$ & $14.1 \%(n=29)$ & $6.8 \%(\mathrm{n}=14)$ & \\
\hline & $11-15$ & $12.1 \%(\mathrm{n}=25)$ & $5.3 \%(\mathrm{n}=11)$ & \\
\hline & $16-20$ & $10.2 \%(n=21)$ & $3.4 \%(\mathrm{n}=7)$ & \\
\hline & $21+$ & $15.5 \%(n=32)$ & $5.8 \%(\mathrm{n}=12)$ & \\
\hline \multirow[t]{3}{*}{ Lightning } & $0-5$ & $21.5 \%(\mathrm{n}=45)$ & $5.3 \%(\mathrm{n}=11)$ & \multirow[t]{3}{*}{$\Sigma=8.312, \mathrm{P}=0.076$} \\
\hline & $6-10$ & $17.2 \%(n=36)$ & $3.8 \%(n=8)$ & \\
\hline & $11-15$ & $17.2 \%(n=36)$ & $0.5 \%(n=1)$ & \\
\hline
\end{tabular}




\begin{tabular}{lllll} 
& $16-20$ & $10.0 \%(\mathrm{n}=21)$ & $3.4 \%(\mathrm{n}=7)$ & \\
& $21+$ & $17.7 \%(\mathrm{n}=37)$ & $3.4 \%(\mathrm{n}=7)$ & \\
Sudden Cardiac Arrest & $0-5$ & $24.9 \%(\mathrm{n}=52)$ & $1.9 \%(\mathrm{n}=4)$ & \\
& $6-10$ & $19.6 \%(\mathrm{n}=41)$ & $1.9 \%(\mathrm{n}=4)$ & \\
& $11-15$ & $17.2 \%(\mathrm{n}=36)$ & - & \\
& $16-20$ & $11.0 \%(\mathrm{n}=23)$ & $2.4 \%(\mathrm{n}=5)$ & \\
$21+$ & $20.0 \%(\mathrm{n}=42)$ & $1.0 \%(\mathrm{n}=2)$ & \\
\hline
\end{tabular}

Key: $\Sigma=$ Fisher's Exact Test 


\section{APPENDIX E}

\section{RECOMMENDATIONS FOR FUTURE RESEARCH}

1. Repeat this study with a larger sample size by attending the WVSSAC pre-season sports meetings to achieve more statistically significant results to better determine coaches' preparedness for sudden death conditions.

2. To assess other state's coaches to determine whether background and education prepared the coach to handle a sudden death situation.

3. To assess what sports had greatest access to a health care provider throughout the season and if the coaches would like to have more access to the health care provider by adding additional questions to the survey.

4. To assess coaching student's awareness and preparedness for sudden death conditions in athletics and whether education properly prepared the coaching students to handle future situations. This would be completed by conducting a survey to current students in athletic coaching majors at universities. 


\section{ADDITIONAL REFERENCES}

65. Definitions. National center for catastrophic sport injury research.

https://nccsir.unc.edu/definition-of-injury/. Accessed October 3, 2018.

66. Cantu RC, Mueller FO. The prevention of catastrophic head and spine injuries in high school and college sports. Br J Sports Med. 2009;43:981-6.

67. Asif IM, Harmon KG. Incidence and etiology of sudden cardiac death: new updates for athletic departments. Sports Health. 2017;9(3):268-279.

68. What is an Automated External Defibrillator? American Heart Association. https://www.heart.org/-/media/data-import/downloadables/pe-abh-what-is-anautomated-external-defibrillator-ucm_300340.pdf. Published 2017. Accessed June 12, 2018.

69. What is CPR? American Heart Association. https://cpr.heart.org/AHAECC/CPRAndECC/AboutCPRECC/WhatIsCPR/UCM_4998 96_What-is-CPR.jsp. Accessed June 12, 2018.

70. Broglio SP, Cantu RC, Gioia GA, et al. National athletic trainers' association position statement: Management of sport concussion. J Athl Train. 2014;49(2):245-265.

71. Guskiewicz KM, Bruce SL, Cantu RC, et al. National athletic trainers' association position statement: Management of sport-related concussion. J Athl Train. 2004;39(3):280-297.

72. McCrory P, Meeuwisse W, Dvorak J, et al. Consensus statement on concussion in sport - the 5 th international conference on concussion in sport held in Berlin, October 2016. Br J Sports Med. 2017.

73. Heck JF, Clarke KS, Peterson TR, Torg JS, Weis MP. National athletic trainers' association postition statement: Spearing in tackle football. J Athl Train. 2004;39(1):101-111.

74. Cervical Spine Injury. Korey Stringer Institute. https://ksi.uconn.edu/emergencyconditions/cervical-spine-injury/. Accessed March 27, 2019.

75. Jimenez CC, Corcoran MH, Crawley JT, et al. National athletic trainers' association position statement: Management of the athlete with type 1 diabetes mellitus. $J$ Athl Train. 2007;42(4):536-545.

76. Hypo/Hyperglycemia. Korey Stringer Institute. https://ksi.uconn.edu/emergencyconditions/hypohyperglycemia/. Accessed March 27, 2019. 
77. Heat Stroke. Korey Stringer Institute. https://ksi.uconn.edu/emergencyconditions/heat-illnesses/exertional-heat-stroke/. Accessed March 27, 2019.

78. Casa DJ, Armstrong LE, Hillman SK, et al. National athletic trainers' association position statement: Fluid replacement for athletes. J Athl Train. 2000;35(2):212-224.

79. Consensus Statement: Sickle Cell Trait and the Athlete. National Athletic Trainers' Association. https://www.nata.org/sites/default/files/SickleCellTraitAndTheAthlete.pdf. Published 2007. Accessed November 27, 2018.

80. Exertional Sickling. Korey Stringer Institute. https://ksi.uconn.edu/emergencyconditions/exertional-sickling/. Accessed March 27, 2019.

81. Drezner JA, Toresdahl B, Rao A, Huszti E, Harmon KG. Outcomes from sudden cardiac arrest in US high schools: A 2-year prospective study from the National Registry for AED use in sports. Br J Sports Med. 2013;47(18):1179-1183.

82. Drezner JA, Courson RW, Roberts WO, Mossesso Jr VN, Link MS, Maron BJ. Interassociation task force recommendations on emergency preparedness and management of sudden cardiac arrest in high school and college athletic programs: A consensus statement. J Athl Train. 2011;12(5):360-375.

83. Adams WM, Mazerolle SM, Casa DJ, Huggins RA, Burton L. The secondary school football coach's relationship with the athletic trainer and perspectives on exertional heat stroke. J Athl Train. 2014;49(4):469-477.

84. Heads Up. Center for Disease Control and Prevention. https://headsup.cdc.gov/. Accessed April 1, 2019.

85. WVSSAC 2017-2018 Participation Survey. https://www.wvssac.org. Accessed April 8, 2019.

86. Office of Certification and Professional Preparation County Approval Process for Initial and Renewal of Coaching, Limited Football Trainer, and Athletic Trainer Authorizations (Form 39). West Virginia Department of Education. https://wvde.state.wv.us/certification/forms/documents/Form39RenewalApprovalGuid eeff.20170814.pdf. Accessed April 8, 2019.

87. Gathers v Loyola Marymount University. Case No. C759027, Los Angeles Super Court (settled 1992).

88. Asthma Recognition. Korey Stringer Institute. https://ksi.uconn.edu/emergencyconditions/asthma/asthma-recognition/. Accessed March 27, 2019. 
89. Traumatic Brain Injury \& Concussion. Centers for Disease Control and Prevention. https://www.cdc.gov/traumaticbraininjury/index.html. Accessed March 27, 2019.

90. Coronado VG, Haileyesus T, Cheng TA, et al. Trends in sports- and recreation-related traumatic brain injuries treated in US emergency departments: The national electronic injury surveillance system-all injury program (NEISS-AIP) 2001-2012. J Head Trauma Rehabil. 2015;30(3):185-197.

91. Wilberger JE. Athletic cervical spinal cord and spine injuries. Neurologic Athletic Head and Spine Injuries. 2000:144-152.

92. Chao S, Pacella MJ, Torg JS. The pathomechanics, pathophysiology and prevention of cervical cord and brachial plexus injuries in athletics. Sports Med. 2010;40(1):59-75.

93. Grundstein AJ, Hosokawa Y, Casa DJ. Fatal exertional heat stroke and American football players: The need for regional heat-safety guidelines. J Athl Train. 2018;53(1):43-50.

94. Yeargin SW, Dompier TP, Casa DJ, Hirschhorn RM, Kerr ZY. Epidemiology of exertional heat illnesses in national collegiate athletic association athletes during the 2009-2010 through2014-2015 academic years. J Athl Train. 2019;54(1):55-63.

95. Incidence of Sickle Cell Trait - United States, 2010. Morbidity and Mortality Weekly Report. Centers for Disease Control and Prevention. 2014;63(49):1155-1158.

96. Mitchell BL. Sickle cell trait and sudden death. Sports Medicine. 2018;4(19):1-6.

97. Harmon KG, Drezner JA, Klossner D, Asif IM. Sickle cell trait associated with a RR of death of 37 times in national collegiate athletic association football athletes: A database with 2 million athletes-years as the denominator. Br J Sports Med. 2012;46:325-330.

98. Lightning Safety: Large Venues. National Weather Service. https://www.weather.gov/safety/lightning. Accessed on April 9, 2019.

99. Lightning. Center for Disease Control and Protection. https://www.cdc.gov/disasters/lightning/index.html. Accessed April 9, 2019.

100. Rao AL, Standaert CJ, Drezner JA, Herring SA. Expert opinion and controversies in musculoskeletal and sports medicine: Preventing sudden cardiac death in young athletes. Arch Phys Med Rehabil. 2010;91(6):958-962.

101. Osterman M, Claiborne T, Liberi V. Radius of care in secondary schools in the midwest: Are automated external defibrillators sufficiently accessible to enable optimal patient care? J Athl Train. 2018;53(4):410-415. 
102. Kurichan VP, Sumner GL, Mitchell LB. Sudden cardiac death. Curr Probl Cardiol. 2015;40(4):133-200.

103. What is Marfan Syndrome? The Marfan Foundation.

https://www.marfan.org/about/marfan. Accessed April 26, 2019. 